\title{
¿Spice and Barrier Layers: An Arabian Sea Case Study
}

\author{
ROSALIND ECHOLS AND STEPHEN C. RISER \\ School of Oceanography, University of Washington, Seattle, Washington
}

(Manuscript received 5 September 2019, in final form 29 December 2019)

\begin{abstract}
Barrier layers (BLs) are a frequent occurrence in low-latitude oceans, but variations in identification methods and quantitative descriptors used, as well as analyses of their lifetimes, lead to differing views on their overall impact. Herein a new method is proposed for identifying BLs that relies on the vertical spice profile rather than arbitrary temperature thresholds. Using 13 years of Argo profiling float data from the Arabian Sea, this method is shown to produce reasonable assessments of BL characteristics in the region. Similarly, use of the spice variable to identify formation mechanisms shows promise for using limited observational data and climatology to reproduce mechanisms proposed from modeling studies. Upper-ocean stability calculations combining profiling float and atmospheric forcing data are used to suggest the most likely one-dimensional mechanisms for erosion of BLs and to calculate the expected lifetimes of BLs throughout the year. Consistent with the evidence about the seasonal spatial extent and frequency of BLs, their duration is expected to be 2-3 times longer during the northeast monsoon than the southwest monsoon. However, the most likely erosion mechanisms vary widely throughout the year, as do the associated changes to the upperocean structure and thus likely impacts on SST.
\end{abstract}

\section{Introduction}

Although much of the ocean is thermally stratified near the surface, there are regions where salinity stratification dominates and can create a density mixed layer (ML) within a much deeper isothermal or thermally inverted layer. The region between the bases of these layers is known as a barrier layer (BL), so termed because it creates a mixing barrier between the base of the ML and the cooler waters of the thermocline (Fig. 1a). BLs were first identified in the western Pacific warm pool (Lukas and Lindstrom 1991) and have subsequently been identified throughout the Indian Ocean (e.g., Sprintall and Tomczak 1992; Qu and Meyers 2005) as well as in subtropical (e.g., Katsura et al. 2015) and high-latitude regions (Kara et al. 2000). Since their discovery, it has been suggested that they may enhance ML warming (Lukas and Lindstrom 1991), minimize the impact of atmospheric forcing on sea surface temperatures (SSTs) (Vialard and Delecluse 1998), or even lead to a decrease in SSTs (Vinyaychandran et al. 2007), and

๑ Denotes content that is immediately available upon publication as open access.

Corresponding author: Rosalind Echols, rechols@uw.edu that they may increase tropical storm intensity (Balaguru et al. 2012; Ffield 2007). This is of particular interest for the high SST in the Arabian Sea that contributes to the onset of the southwest monsoon (Rao and Sivakumar 1999; Masson et al. 2005; Shenoi et al. 1999).

One of the challenges of observational BL studies is that several different definitions are employed for the ML and isothermal layer. Lukas and Lindstrom (1991) used a density gradient criterion $\left(\leq 0.01 \mathrm{~kg} \mathrm{~m}^{-4}\right)$ to identify the lower boundary of the ML, and temperature and salinity gradient criteria with roughly equivalent impacts on density to identify the thermocline and halocline. Subsequent work has primarily used a change in temperature to identify the depth of the isothermal layer, using the corresponding density change to denote the ML depth. However, the values used for the temperature threshold vary among $0.2^{\circ} \mathrm{C}$ (de Boyer Montégut et al. 2014, hereafter CdBM2014), $0.5^{\circ} \mathrm{C}$ (Vialard and Delecluse 1998), $0.8^{\circ} \mathrm{C}$ (Qu and Meyers 2005), and $1^{\circ} \mathrm{C}$ (Durand et al. 2004, 2007; Thadathil et al. 2008; Agarwal et al. 2012). As a result, each of these studies references a different segment of the water column and produces different ML and BL characteristics. Arabian Sea studies alone exhibit a wide range of observations of the frequency and thickness of these layers, differing substantially within a single season. The precise details of the ML definition 

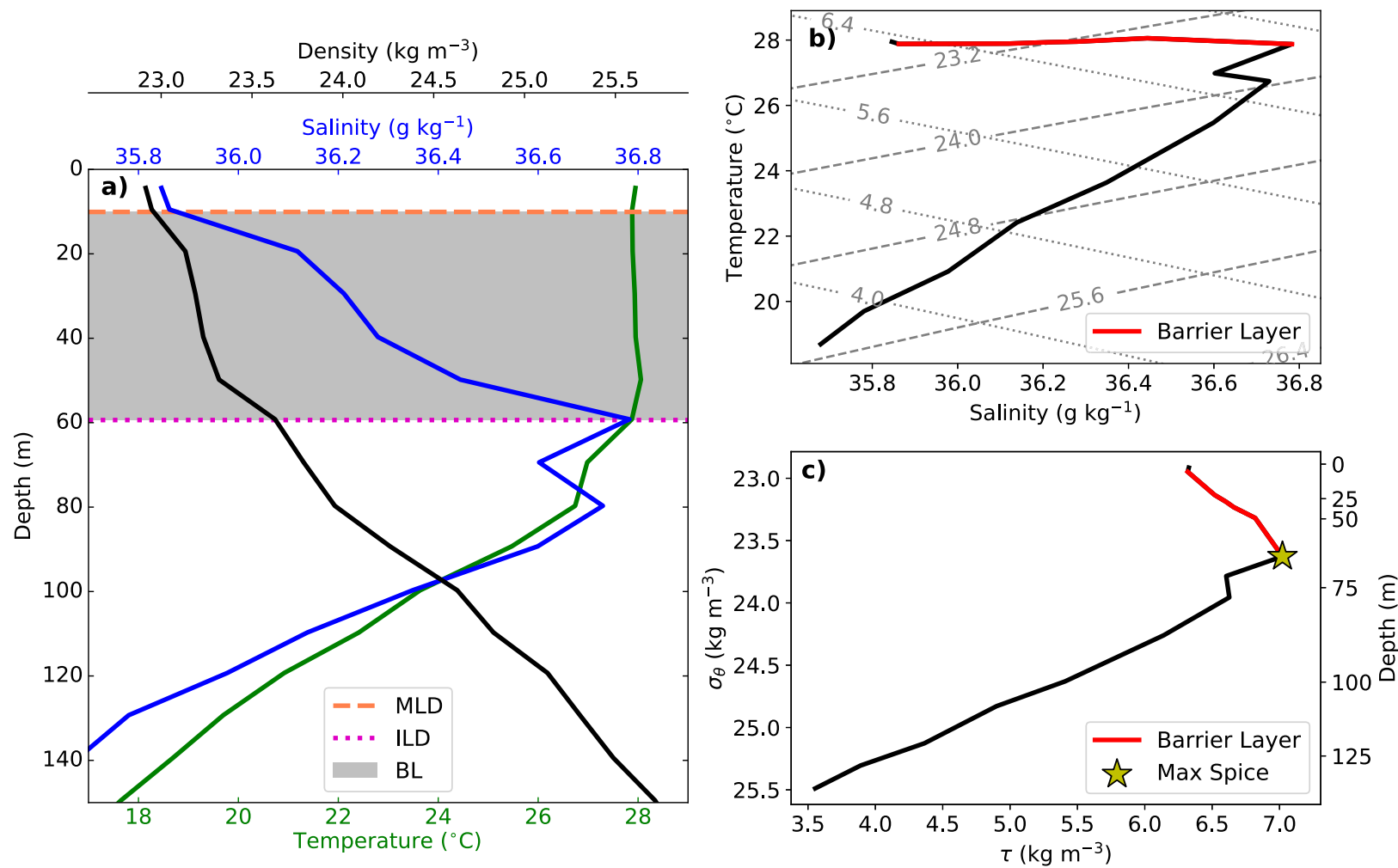

FIG. 1. Data from Argo float 2900258, 28 Jan $2004,11.98^{\circ} \mathrm{N}, 69.719^{\circ} \mathrm{E}$ : (a) temperature, salinity, and density profiles from the float. Mixed layer depth is indicated by the orange dashed line, with isothermal layer depth indicated by the magenta dotted line. The gray shaded area is the section of the water column termed the BL. (b) The $T-S$ diagram corresponding to profile in (a). The red portion of line indicates the BL. Dashed gray lines are potential density contours, and dotted gray lines are spice contours (both $\mathrm{kg} \mathrm{m}^{-3}$ ). (c) Potential density-spice diagram. The red-shaded section is as in (b). The yellow star indicates the location of maximum spice. Plots show different representations of the same segment of the water column.

have implications for estimates of how long BLs persist, what causes their ultimate erosion, and their impact on ML heat budgets; BLs of the same thickness located at different depths or with different degrees of stratification are likely to have different responses to atmospheric forcing. Thus, disparities in the portion of the water column referenced as the "BL" and the characteristics of this layer can be significant.

Due to the near-isothermal (but not isohaline) nature of the upper water column when a BL is present (Fig. 1a), the near-surface temperature-salinity relationship of a BL appears on a $T-S$ diagram (Fig. 1b) as a roughly horizontal portion of the near-surface profile (Fig. 1b, red segment). To quantify the "flatness" of this tail, we can examine the density ratio

$$
R_{\rho}=\frac{\alpha\left(T_{C}\right)_{z}}{\beta\left(S_{\mathrm{A}}\right)_{z}}
$$

where $\alpha=-(1 / \rho)\left(\partial \rho / \partial T_{C}\right)$ and $\beta=(1 / \rho)\left(\partial \rho / \partial S_{\mathrm{A}}\right), \rho$ is potential density referenced to the sea surface, $T_{C}$ is Conservative Temperature, $S_{\mathrm{A}}$ is Absolute Salinity, and subscript $z$ refers to a vertical derivative (IOC et al. 2010), with $z$ defined as positive upward. Here $R_{\rho}$ indicates the relative contributions of temperature and salinity stratification to changes in density (Schmitt 1981, 1990). In a BL, where vertical changes in salinity dominate the changes in density and $\left(T_{C}\right)_{z} \approx 0$, we expect that $R_{\rho} \approx 0$. The only exception to this would be in the presence of a relatively strong temperature inversion, in which case $R_{\rho}$ would be small and positive $\left[\left(T_{C}\right)_{z}\right.$ and $\left(S_{\mathrm{A}}\right)_{z}$ are both negative, but $\left|\alpha\left(T_{C}\right)_{z}\right|<$ $\left|\beta\left(S_{\mathrm{A}}\right)_{z}\right|$ for a salinity stratified, stable water column]. Similarly, a small negative density ratio $\left(0>R_{\rho} \gg-1\right)$ would indicate weak, positive temperature stratification with a stable salinity stratification dominating. The density ratio also indicates conditions in which double-diffusion in the form of convective overturning or salt-fingering are likely to occur (Schmitt 1990), both of which are possibilities within BLs. When a temperature inversion occurs, relatively cool, freshwater overlays warmer, saltier water within the BL, resulting in conditions possibly favorable to convective overturning. The bottom of the BL coincides with a region 
of relatively high temperature and salinity; if the bottom of the BL coincides with the beginning of the main thermocline, as originally defined by Lukas and Lindstrom (1991), the water is cooler and fresher below, setting up conditions possibly favorable to salt-fingering (Schmitt 1990). We do not expect to be able to observe these dynamical processes directly in data from in situ data collected from ships or profiling floats; additionally the effects of shear may be important in many cases (Schmitt 1990), but nonetheless BLs may be susceptible to erosion in this way.

While BLs are not the only phenomenon associated with subsurface salinity maxima, they are unique among upper-ocean stratification regimes in mid- and low latitudes in that the saltiness of the water column increases below the ML and peaks near the bottom of a roughly isothermal layer, inviting the use of the variable known as spice to describe them. Along an isopycnal, increases (decreases) in temperature must be counteracted by increases (decreases) in salinity (Jackett and McDougall 1985) and spice characterizes those changes in the relative warmth and saltiness of a water parcel (Veronis 1972; Flament 2002). Although the concept of spice has appeared in several different forms since its inception and construction of a full definition requires a specific reference point, here we will follow the lead of Shcherbina et al. (2009) in referencing the approximate differential form

$$
d \tau=\rho(\alpha d \theta+\beta d S)
$$

where $\tau$ denotes spice, $\rho$ represents the reference density, and the parentheses indicate multiplication. For a given $\rho$, increases (decreases) in potential temperature, salinity, or both, can lead to an increase (decrease) in spiciness. This is a direct analog of the differential form for density (when neglecting pressure contributions), but with the sign of the $\alpha d \theta$ term reversed.

Vertical variations in spice can indicate the layering of different water types (Shcherbina et al. 2009). Just as BLs occur when $R_{\rho} \approx 0$ at the base of the mixed layer, they likewise occur when spice increases with depth primarily due to salinity, since spice and density increase concurrently with increasing salinity in an isothermal layer. Temperature inversions can contribute to an increase in spice with depth, but this is only possible in a stable water column if $0<R_{\rho}<1$ (i.e., the water column is stabilized by salinity). Thus, BLs in mid- and low latitudes can be characterized as occurring when spice increases with depth (or density) from the surface as shown in Fig. 1c. All other scenarios of relative temperature and salinity stratification lack this feature.

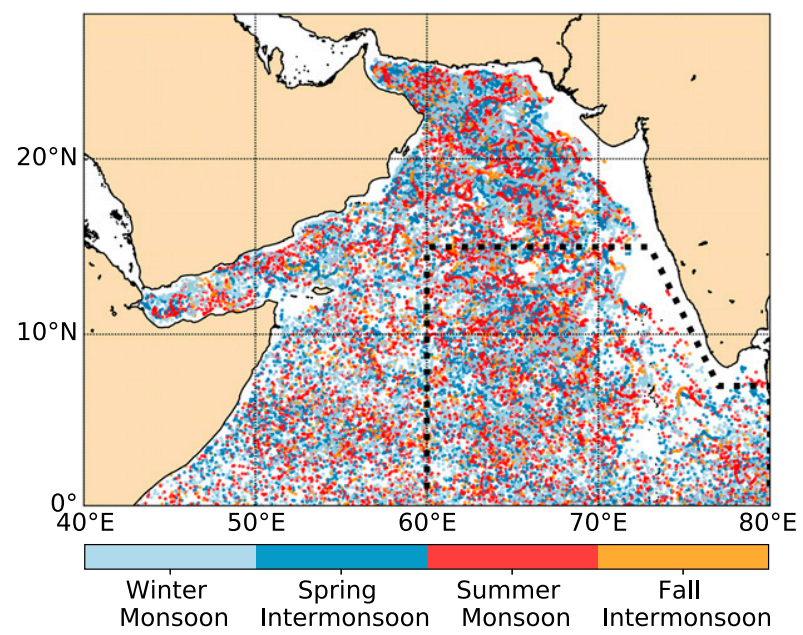

FIG. 2. Distribution of profiling float data in the Arabian Sea, from 2004 to 2016. Each dot indicates one profile, color-coded by season. The black-dashed area indicates the SEAS definition for use in this study.

In this study, we aim to remove some of the ambiguity surrounding BL identification and use this to improve the quantitative estimates of BL presence in the Arabian Sea. We do this by proposing a method for identifying the presence of a BL relying on the vertical spice profile. We also address questions of BL formation, persistence, and erosion mechanisms more quantitatively than was previously possible from observational data, using spice to assess variations in temperature and salinity simultaneously. We focus on the Arabian Sea as the study area due to its importance in the monsoon cycle, particularly the elevated sea surface temperatures observed during the spring intermonsoon, which previous studies have suggested may be influenced by BL (e.g., Durand et al. 2004). The region also exhibits broad variation in the salinity stratification observed throughout the year, rendering of suitably determining the BL somewhat complex.

\section{Data}

This study uses data from Argo-type floats in the Arabian Sea, here considered to be the region bounded by the equator in the south and the Persian Gulf in the north, spanning longitudes of $40^{\circ}$ and $80^{\circ} \mathrm{E}$ (Fig. 2). Initially, all available temperature and salinity profiles from 2004 to 2016 were considered, including both delayed mode and real time/adjusted profiles. Since not all of these profiles had completed full quality control measures, the utility of each profile was individually assessed. Any profile lacking data in the top $10 \mathrm{~m}$ was discarded, as were profiles with temperature $T$ and salinity $S$ values outside a reasonable range for 
this location $\left(0<T<35^{\circ} \mathrm{C} ; 20<S<40\right)$. Profiles whose maximum pressure was less than $100 \mathrm{~m}$, or profiles with large gaps in the pressure data, were also excluded from the analysis. After these quality control measures (which resulted in discarding roughly $34 \%$ of the original profiles) there were a total of 34311 useable profiles of temperature and salinity. In contrast with previous studies looking at the seasonal patterns of BLs in the Arabian Sea (e.g., Thadathil et al. 2008), most $2^{\circ} \times 2^{\circ}$ boxes in the primary study area, the southeast Arabian Sea (SEAS), have over 100 profiles annually per box, and many have considerably more. Here, we use a slightly larger definition of the SEAS from other studies, focusing on the region between $60^{\circ}$ and $80^{\circ} \mathrm{E}$ and from the equator to $15^{\circ} \mathrm{N}$, as this definition captures the region where BLs are seen most frequently across all seasons (black outlined region in Fig. 2) and may have an impact on the development of the mini warm pool during the spring intermonsoon.

We used the Monthly Isopycnal/Mixed-Layer Ocean Climatology (MIMOC) Conservative Temperature and Absolute Salinity fields to represent long-term averages in the temperature and salinity fields (Schmidtko et al. 2013). Absolute Salinity $S_{\mathrm{A}}$ indicates the mass fraction of salt in seawater $\left(\mathrm{g} \mathrm{kg}^{-1}\right)$. Although the differences between conservative and potential temperature, and practical and absolute salinity, are small near the surface where this study is conducted, both Conservative Temperature $T_{C}$ and Absolute Salinity are necessary for using the Thermodynamic Equations of State-2010 (TEOS-10) (Feistel 2003; IOC et al. 2010). In this paper, we use TEOS-10 to calculate spice (via the variability of isopycnal temperature and salinity; McDougall and Krzysik 2015) and potential density (the density a fluid parcel would acquire if it were brought adiabatically to the surface), as well as to convert in situ temperature and salinity to $T_{C}$ and $S_{\mathrm{A}}$. A comparison of the results of this spice calculation with the Flament (2002) formulation yield very similar results. The National Centers for Environmental PredictionDepartment of Energy (NCEP-DOE) Reanalysis-2 daily average heat fluxes, precipitation, and wind fields were used to calculate approximate real-time fluxes associated with individual profiles, and NCEP/NCAR Reanalysis1 monthly long term mean (1981-2010) data were used to represent long term averages of these same quantities to develop a climatology. Both of these are based on state-of-the-art reanalysis/forecast with data assimilation (Kanamitsu et al. 2002).

\section{Identifying and describing barrier layers}

The established method for identifying BLs involves approximating the bottom of a near-isothermal layer with a temperature threshold and the bottom of the density ML (if different) with the corresponding change in density,

$$
\begin{aligned}
z_{\mathrm{IL}} & =z\left(T=T_{r}+\Delta T\right), \\
z_{\mathrm{ML}} & =z\left(\sigma_{\theta}=\sigma_{\theta, r}+\Delta T \frac{\partial \sigma_{\theta}}{\partial T}\right), \\
h_{\mathrm{BL}} & =z_{\mathrm{IL}}-z_{\mathrm{ML}},
\end{aligned}
$$

where $z_{\mathrm{IL}}$ represents the depth of the isothermal layer, $T_{r}$ is the temperature at a reference pressure (typically $10 \mathrm{dbar}), z_{\mathrm{ML}}$ is the depth of the ML, $\sigma_{\theta, r}$ is the density at a reference pressure $r$, and $h_{\mathrm{BL}}$ is the thickness of the BL. $\Delta T$ is the change in temperature selected to indicate the bottom of the isothermal layer. As noted earlier, we find a range of values between $-0.2^{\circ}$ and $-1.0^{\circ} \mathrm{C}$ being used for $\Delta T$ in previously published BL studies in the Arabian Sea. Also, seasonal variations in the strength of stratification within the BL suggest that a particular threshold may not capture comparable segments of a water column in different seasons, making comparisons between seasons less meaningful. There are also situations in which temperature and salinity contribute nearly equally to the density stratification in such a way as to create a mismatch between the isothermal layer and ML as defined above, without necessarily signifying a genuine BL.

An alternative approach is to examine the properties of the vertical spice profile. For a BL to occur in a gravitationally stable profile, a low-spice, low-density water mass must be layered above a high-spice, higherdensity water mass (Fig. 1); the bottom of the BL corresponds to a transition to a regime in which thermal stratification dominates, therefore returning to a lowerspice regime (Fig. 1c). Each of these spice transitions occurs diapycnally, as the BL is defined by a change in density (Fig. 1a). To identify suitable layer definitions for the mixed and isothermal layers, we can therefore look for inflection points in the profile of spice versus density, indicating transitions between stratification regimes. In doing so, we are identifying just the portion of the water column where salinity stratification controls the density as the BL; this excludes profiles where temperature and salinity contribute equally, and does not require the preselection of a temperature threshold or gradient that is compatible with the strength of the salinity stratification for identifying BL. We use a peak detection method as discussed by Shcherbina et al. (2009), who referred to the curvature in a spice versus density profile as diapycnal spiciness curvature $\tau_{\sigma \sigma}$, where the subscripts denote derivatives with respect to potential density. High absolute values of $\tau_{\sigma \sigma}$ correspond 

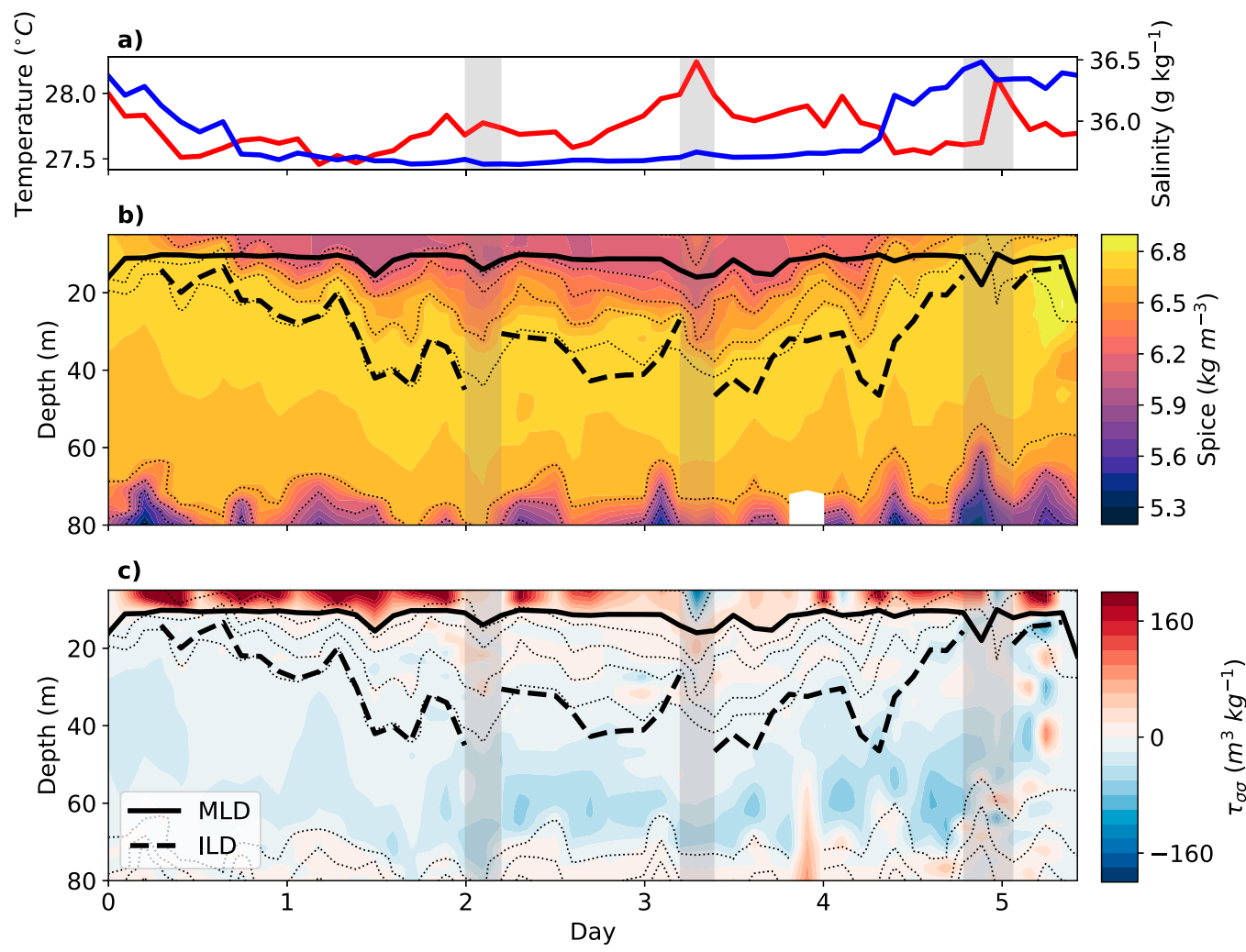

FIG. 3. Data from part of a 12-day, $\sim 2$-hourly cycle routine during February 2015 near $13^{\circ} \mathrm{N}, 6^{\circ} \mathrm{E}$ (profiling float 2902174). (a) Surface temperature (red) and salinity (blue), (b) spice, and (c) diapycnal spiciness curvature. The solid black line is mixed layer depth, and the dashed black line is isothermal layer depth. Both depths are determined using the spice method. Highlighted regions depict temporary BL erosion.

to sharp diapycnal transitions in water mass properties (Shcherbina et al. 2009). A positive $\tau_{\sigma \sigma}$ peak indicates a transition point from lower to higher spice (as happens at the base of the ML when a BL is present), whereas a negative peak indicates a transition from higher to lower spice (as happens at the bottom of the barrier/isothermal layer). These patterns can be observed qualitatively in Fig. 3, where a clear low-spice signal and high $\tau_{\sigma \sigma}$ dominate the mixed layer, whereas the reverse is true within the BL. This is similar in spirit to the method developed by Lorbacher et al. (2006) for ML identification, but relies on the spice profile rather than the temperature profile.

In our analysis we linearly interpolate each spice profile to a $0.01 \mathrm{~kg} \mathrm{~m}^{-3}$ grid and then apply a Gaussian filter with a standard deviation of $0.01 \mathrm{~kg} \mathrm{~m}^{-3}$ to remove some of the noise. For older float profiles with lower vertical measurement resolution this might not be necessary, but this method is effective for applying the same algorithm to all available measurements. Using a smaller grid $\left(0.005 \mathrm{~kg} \mathrm{~m}^{-3}\right)$ produces a greater than $97 \%$ agreement in both BL identification and thickness; the choice of grid primarily needs to be small enough to resolve the density features. For comparison to the threshold method, $\Delta T=-0.2^{\circ} \mathrm{C}$ translates to $\Delta \rho \approx$ $0.06 \mathrm{~kg} \mathrm{~m}^{-3}$ for the region considered here. Any profiles where a maximum in spice was found in the two uppermost measured values of $T$ and $S$ were labeled non-BLs and excluded from the remainder of the algorithm; for these profiles, a temperature threshold of $\Delta T=-0.2^{\circ} \mathrm{C}$ was found to be sufficient for identifying the base of the $\mathrm{ML}$ in this region. The $\tau_{\sigma \sigma}$ was calculated using a central difference formula and smoothed again using the same Gaussian filter as described above to remove noise introduced by taking derivatives. A profile that has the spice characteristics of a BL has a positive first peak in $\tau_{\sigma \sigma}$, corresponding to a transition from low spice to high spice; this is the base of the ML (orange line, Fig. 4b). A deeper negative peak, corresponding to a transition from high spice to low spice indicates the base of the isothermal layer. When more than one possible negative peak existed, the peak nearest the depth of maximum spice was used as this represented the depth to which the salinity stratification dominates density. Figure $4 \mathrm{~b}$ shows a profile with a weak negative $\tau_{\sigma \sigma}$ peak much shallower than the maximum spice, and another much larger peak 

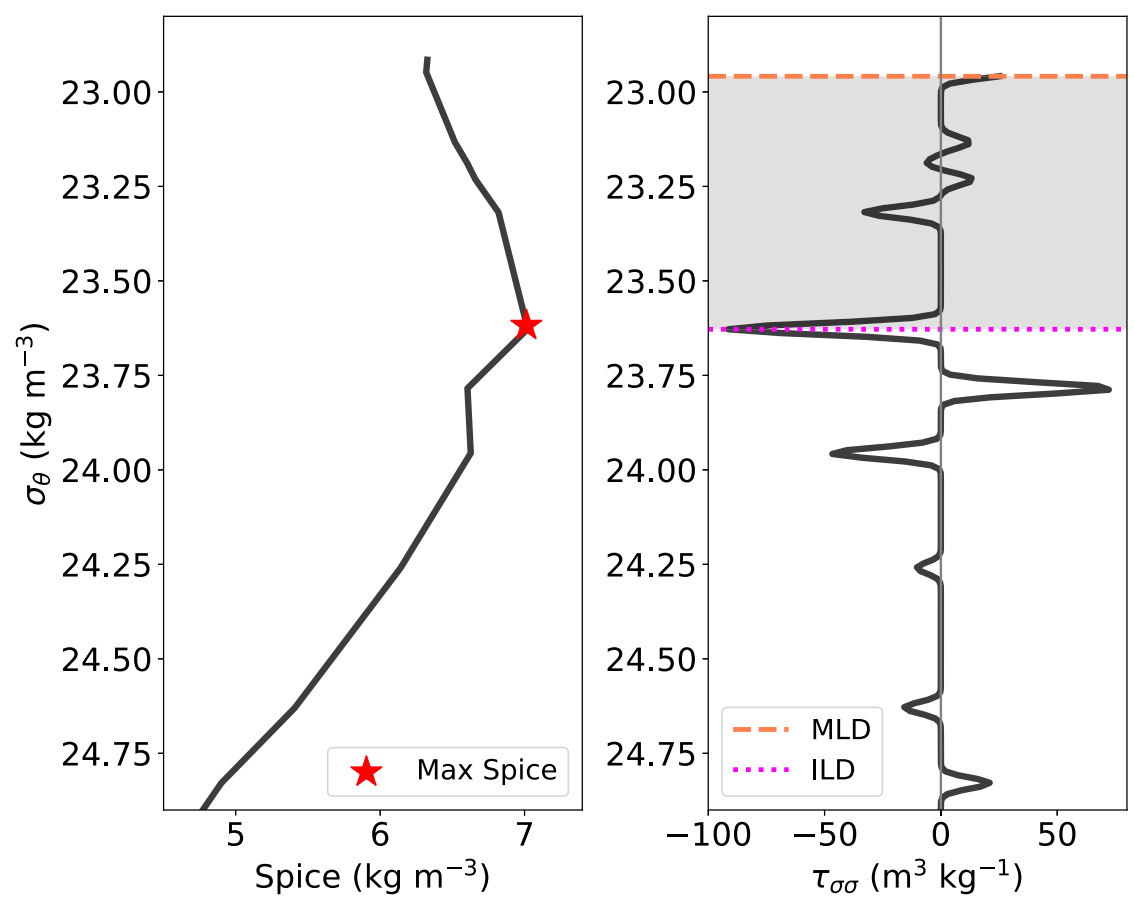

FIG. 4. The $\tau_{\sigma \sigma}$ peak locations used for defining the mixed layer depth (orange dotted line) and isothermal layer depth (magenta dashed line). Note the correspondence between the maximum spice (red star) and isothermal layer depth. This profile shows a relatively nonnoisy profile with clearly dominant peaks near the densities of interest. The gray shaded region corresponds to the BL. Same float profile as for Fig. 1.

at the same depth as the maximum spice; the latter was selected as the base of the BL. Once the two peaks were identified in the spice versus density profile, the corresponding pressure levels were then used as the ML depth and the equivalent of the isothermal layer depth. The BL thickness is defined as in Eq. (3). The results of this method are shown on a standard depth profile in Fig. 1a. Due to the nature of the data used, which has limited measurements within the top $10 \mathrm{~m}$, the analysis here focuses primarily on monthly and seasonal patterns. However, if data with sufficient nearsurface resolution were available, this method could also be applied to explore shorter time scales without major modification as it would provide the depths of changes in stratification.

In previous studies, the quantity porosity has been used as a measure of the longevity and spatial extent of BLs (Mignot et al. 2009; CdBM2014). Here, instead, we quantify the frequency with which BLs are observed by dividing profiles into $2^{\circ} \times 2^{\circ}$ boxes and calculating the percentage of profiles in a given box that are identified as BLs (effectively $100 \%$ - porosity). Mignot et al. (2009) used five profiles per $2^{\circ} \times 2^{\circ}$ box as their minimum number for robust statistics; the data coverage available here easily meets this minimum in the SEAS outside of coastal areas. Figure 5 shows the BL frequency by season. In comparing this with the spatial distribution of BLs shown in other studies (Agarwal et al. 2012; CdBM2014), we find that the results are generally most similar during the northeast monsoon. We find that the BLs reach farther west than suggested by some others, who found very few BLs west of $68^{\circ} \mathrm{E}$ (Agarwal et al. 2012). Differing spatial distributions of the datasets used may account for the nuances in some of the differences. In comparison with Thadathil et al. (2008), we find that the distribution of BLs is shifted toward the southeast, where little data were available at the time of that study. In comparison with CdBM2014 we find evidence of BLs farther north and east than in their south central Arabian Sea study box.

We also calculate BL characteristics for comparison to previous studies. BLs in the Arabian Sea demonstrate a seasonal cycle that strongly correlates with the southwest and northeast monsoons, with peaks in thickness in February and August. Figure 6b shows the thickness and frequency averaged over the entire basin and suggests that the peak average thickness of BLs in February and August are roughly comparable, with values of approximately $35 \mathrm{~m}$. Previous studies have identified values ranging from 5 to $60 \mathrm{~m}$ for the southwest monsoon 

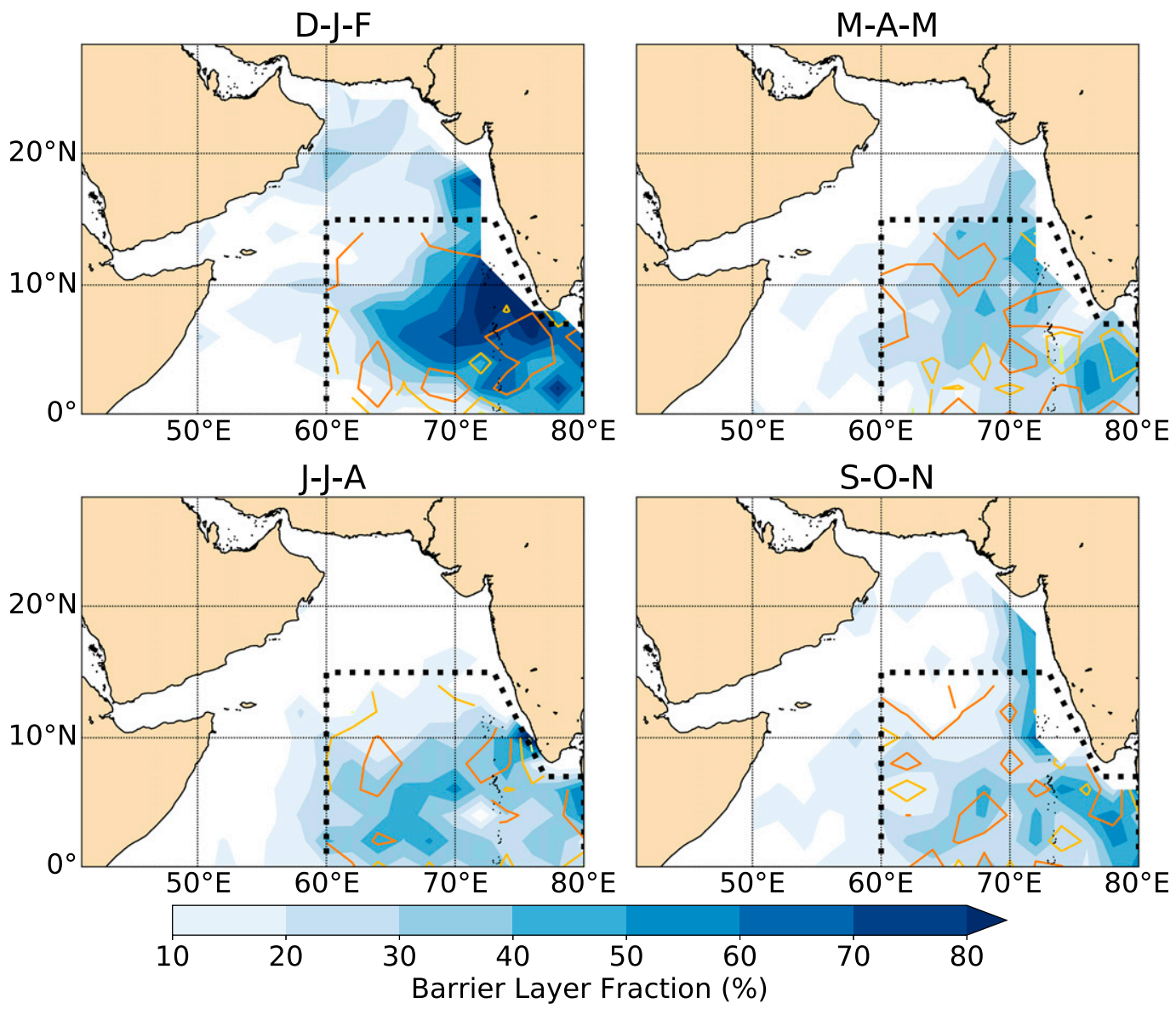

FIG. 5. Frequency (blue filled contours) and thickness (orange line contours, SEAS only) of BL by season. Thickness contours are at $30 \mathrm{~m}$ (light orange) and $40 \mathrm{~m}$ (dark orange). The black-dashed area indicates the SEAS definition for use in this study.

(CdBM2014, and references therein), and from 30 to $50 \mathrm{~m}$ for the northeast monsoon (Shenoi et al. 2004; Durand et al. 2004; Agarwal et al. 2012). In this regard, the spice method produces results that fall within the range of previously calculated values. Comparing Fig. 5 to previous plots of barrier layer thickness (CdBM2014; Agarwal et al. 2012; Durand et al. 2007) indicates that the barrier layers found here tend to have the most similar distribution and thickness during the northeast monsoon, although we do not find regions with BL thickness $>60 \mathrm{~m}$, when averaged in a $2^{\circ} \times 2^{\circ}$ box; during the southwest monsoon, we find them to be thicker and existing farther west. A major difference between the results here and those reported previously is that the depths calculated for the ML and BL here specifically indicate transitions in the stratification regime.

BL thickness does not fully capture the strength of BLs, important when considering their impact and ultimate erosion. Chi et al. (2014) suggested BL potential energy $P_{\mathrm{BL}}$ as a more suitable measure of the strength of a BL. The $P_{\mathrm{BL}}$ incorporates the thickness of a BL, but also considers ML depth and strength of stratification within the BL. It is defined as $P_{\mathrm{BL}}=P_{\mathrm{mix}}-P_{0}$, where

$$
P_{\text {mix }}=-g \int_{z_{\mathrm{ILD}}}^{0} \overline{\rho(z)} z d z=-\frac{1}{2} g \overline{\rho(z)} z_{\mathrm{ILD}}^{2}
$$

and

$$
\begin{aligned}
P_{0}= & -g \int_{z_{\mathrm{ILD}}}^{0} \rho(z) d z=-g\left[\int_{z_{\mathrm{MLD}}}^{0} \rho(z) z d z\right. \\
& \left.+\int_{z_{\mathrm{ILD}}}^{z_{\mathrm{MLD}}} \rho(z) z d z\right] .
\end{aligned}
$$

Here $P_{\text {mix }}$ is the potential energy the water column would have after mixing downward to the base of the isothermal layer, and $P_{0}$ is the initial potential energy of the water column. The overbar indicates a vertical 

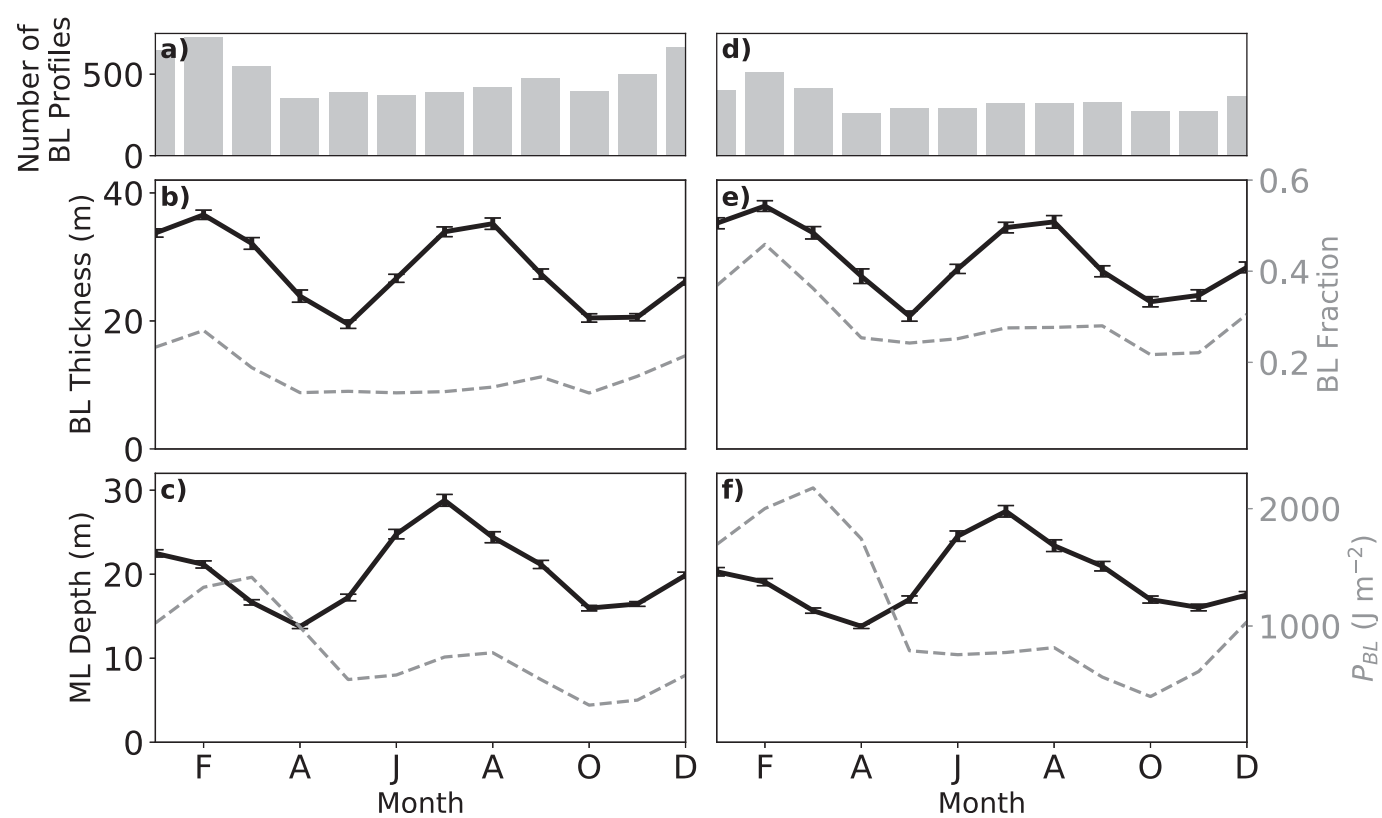

FIG. 6. BL statistics for the Arabian Sea. (a) Number of BL profiles observed monthly in Arabian Sea. (b) BL thickness is indicated by the black line (left $y$ axes), the dashed gray line indicates the BL fraction (right $y$ axes). (c) ML depth is indicated by the black line (left $y$ axes), the dashed gray line indicates the $P_{\mathrm{BL}}$ (right $y$ axes). Error bars are standard error. (d)-(f) As in (a)-(c), but for SEAS.

average. A large positive value of $P_{\mathrm{BL}}$ would indicate a large increase in potential energy associated with mixing away the BL, requiring significant input of kinetic energy. This formulation gives a better quantitative estimate of the relative difficulty of eroding BLs through the input of mechanical energy than the thickness. Figure $6 \mathrm{c}$ shows that despite comparable BL thicknesses in February and August, ML depths are shallower yet the overall $P_{\mathrm{BL}}$ is substantially higher during February. Figures $6 \mathrm{~d}$ and $6 \mathrm{f}$ focus exclusively on the SEAS; the results show similar patterns to Figs. $6 \mathrm{a}$ and $6 \mathrm{c}$, consistent with the fact that more than two-thirds of the BL profiles observed are in the SEAS. These results suggest that the new BL identification method described here produces reasonable results.

\section{Formation of barrier layers}

Applications of spice to BLs are not limited to identifying these layers. Figure 7 illustrates the possible mechanisms by which BLs could be formed (Cronin and McPhaden 2002, hereafter CM2002), illustrated in terms of the necessary spice and density conditions of the water parcels involved. In Fig. 7a, a horizontal spice front ( $\tau_{\text {low }}$ and $\rho_{\text {low }}$ to the left; $\tau_{\text {high }}$ and $\rho_{\text {high }}$ to the right) is tilted into the vertical by a vertical shear in the horizontal velocity. The simultaneous low spice and low density come about due to a lower-salinity water mass on the left, uncompensated by temperature. After tilting, the vertical profile at the original front location will have low spice above higher spice, necessarily setting up a BL. Figure $7 \mathrm{~b}$ shows a low-spice, low-density water mass being advected into a region of higher spice and density, establishing a BL where the two water masses overlap. The reverse process, where high-spice, high-density water is advected and ultimately subducted under the lowerspice and lower-density water mass would also form a barrier layer. The final formation mechanism comes about as a result of rainfall, illustrated in Fig. 7c. As with the previous two cases, the surface water in this case must have lower spice and density than the water mass on which it is superimposed in order to form a BL. In all cases, low salinity largely controls both the density and the spice. Cooler water can contribute to the low spice, but in order to establish the necessary stable vertical profile, $\left|R_{\rho}\right|<1$.

To explore these formation processes more quantitatively, we can first examine the vertical derivatives of the temperature and salinity tendency as done by CM2002,

$$
\begin{aligned}
S_{z t}= & -\mathbf{U} \cdot \nabla S_{z}-w S_{z z}-\mathbf{U}_{z} \cdot \nabla S-w_{z} S_{z}-\left(\overline{w^{\prime} S^{\prime}}\right)_{z z} \\
T_{z t}= & -\mathbf{U} \cdot \nabla T_{z}-w T_{z z}-\mathbf{U}_{z} \cdot \nabla T-w_{z} T_{z} \\
& -\left(\overline{w^{\prime} T^{\prime}}\right)_{z z}+\frac{1}{\rho c_{p}}\left(Q_{\mathrm{rad}}\right)_{z z}
\end{aligned}
$$


(a)

(b)

(c)
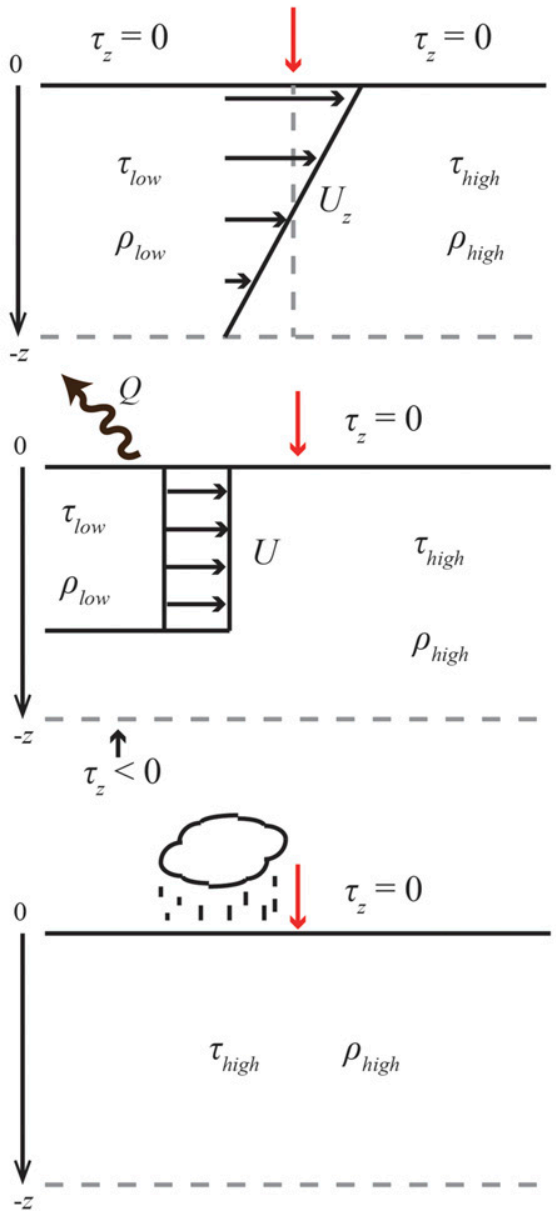
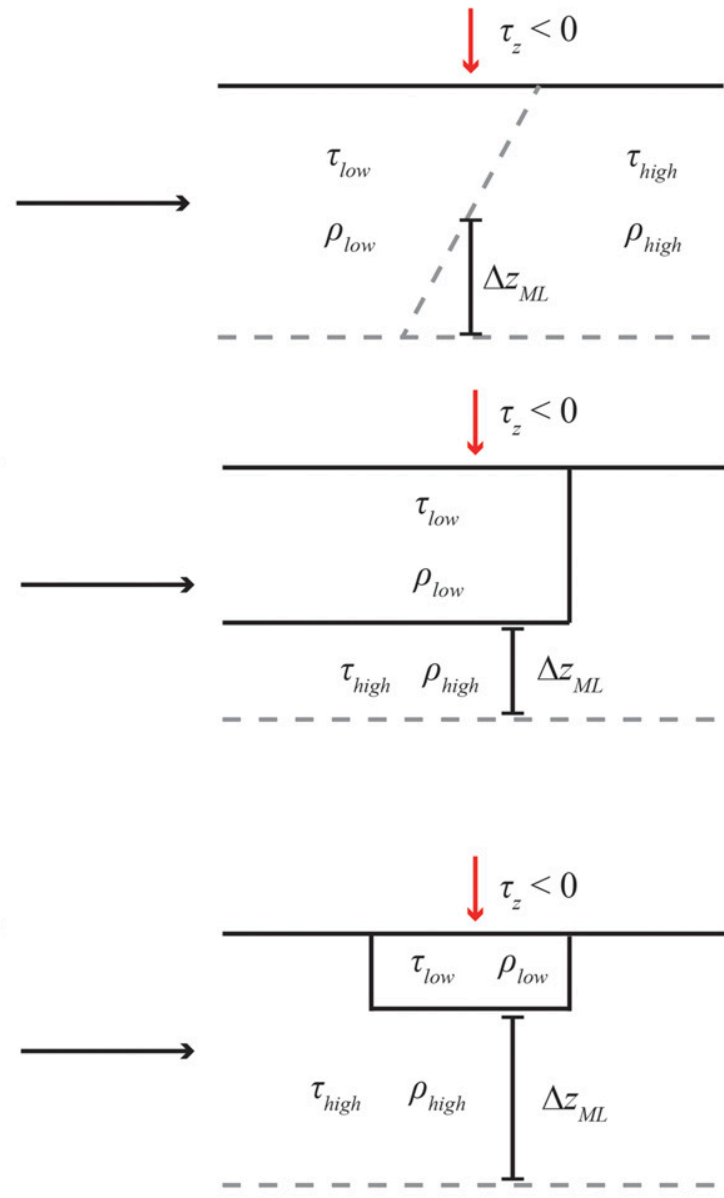

FIG. 7. A schematic showing mechanisms of BL formation in terms of spice corresponding to (a) frontal tilting [term 3 on right side of Eq. (11)]; (b) advection of freshwater [term 1 on right side of Eq. (11)], with possible surface cooling (term 5); and (c) the rain-formed BL, requiring some wind stirring to mix the freshening downward [term 5 on right side of Eq. (11)]. The red arrow shows the location of the observation.

In these equations $\mathbf{U}$ represents the horizontal velocity, $w$ the vertical velocity, and $\nabla$ the horizontal gradient operator. The term $\left(\overline{w^{\prime} S^{\prime}}\right)_{z z}$ is the vertical turbulent flux of salinity, equal to $S_{0}(P-E)$ at $z=0$, where $P$ and $E$ indicate precipitation and evaporation and $S_{0}$ is the surface salinity. The term $\left(\overline{w^{\prime} T^{\prime}}\right)_{z z}$ represents the vertical turbulent flux of temperature; $\left(\overline{w^{\prime} T^{\prime}}\right)_{z z}$ at $z=0$ represents the contributions of latent, sensible, and longwave radiation, while $Q_{\text {rad }}$ represents the shortwave radiation.

This formulation highlights the processes shown in Fig. 7 in terms of the temperature and salinity tendencies, including the advection of freshwater (term 1 on the right side of each equation), rain (term 5 on the right side of each equation), and tilting of a horizontal salinity gradient through vertical shear (term 3 on the right side of each equation) (CM2002). As pointed out in CM2002, the terms involving vertical velocity do not contribute to the initial formation of BLs; however, $w_{z}$ can stretch a BL that already exists and $w$ can vertically displace an existing BL without altering its structure otherwise. The reverse of each of these processes can also contribute to BL erosion, including through mechanisms such as upwelling and advection of high-salinity water (Shenoi et al. 2004).

Rather than considering salinity and temperature separately, we return to the consideration of spice as an indicator of a BL, consistent with the schematic representation of Fig. 7. We use a linear combination of Eqs. (6) and (7) above to examine the vertical derivative of the spice tendency $\tau_{z t}$ (neglecting variations in $\alpha$ and $\beta$ ) to find that

$$
\tau_{z t}=\rho\left(\alpha \theta_{z t}+\beta S_{z t}\right) .
$$

Substituting Eqs. (6) and (7) into Eq. (8) yields 


$$
\begin{aligned}
\tau_{z t}= & \rho\left\{\alpha \left[-\mathbf{U} \cdot \nabla T_{z}-w T_{z z}-\mathbf{U}_{z} \cdot \nabla T-w_{z} T_{z}\right.\right. \\
& \left.-\left(\overline{w^{\prime} T^{\prime}}\right)_{z z}+\frac{1}{\rho c_{p}}\left(Q_{\mathrm{rad}}\right)_{z z}\right]+\beta\left[-\mathbf{U} \cdot \nabla S_{z}-w S_{z z}\right. \\
& \left.\left.-\mathbf{U}_{z} \cdot \nabla S-w_{z} S_{z}-\left(\overline{w^{\prime} S^{\prime}}\right)_{z z}\right]\right\},
\end{aligned}
$$

or

$$
\begin{aligned}
\tau_{z t}= & \rho\left\{\left[-\mathbf{U} \cdot\left(\alpha \nabla T_{z}+\beta \nabla S_{z}\right)-w\left(\alpha T_{z z}+\beta S_{z z}\right)\right.\right. \\
& \left.-\mathbf{U}_{z} \cdot(\alpha \nabla T+\beta \nabla S)-w_{z}\left(\alpha T_{z}+\beta S_{z}\right)\right] \\
& \left.-\alpha\left[\left(\overline{w^{\prime} T^{\prime}}\right)_{z z}-\frac{1}{\rho c_{p}}\left(Q_{\mathrm{rad}}\right)_{z z}+\beta\left(\overline{w^{\prime} S^{\prime}}\right)_{z z}\right]\right\} .
\end{aligned}
$$

In final form, this yields

$$
\begin{aligned}
\tau_{z t}= & -\mathbf{U} \cdot \nabla \tau_{z}-w \tau_{z z}-\mathbf{U}_{z} \cdot \nabla \tau-w_{z} \tau_{z}-\rho\left\{\alpha \left[\left(\overline{w^{\prime} T^{\prime}}\right)_{z z}\right.\right. \\
& \left.\left.-\frac{1}{\rho c_{p}}\left(Q_{\mathrm{rad}}\right)_{z z}\right]+\beta\left(\overline{\left(w^{\prime} S^{\prime}\right.}\right)_{z z}\right\} .
\end{aligned}
$$

BLs are the only gravitationally stable condition with $\tau_{z}<0$ near the surface, since the change in salinity with depth that produces increasing spice $(\beta d S)$ also increases the density. When considering a mechanism such as the tilting of a salinity front by vertical shear of the horizontal velocity [term 3 on the right side of Eq. (11)], identifying a salinity front is therefore insufficient for locating likely areas of BL formation. A salinity front fully compensated by temperature (cool on the fresh side, warm on the salty side) would not establish any density stratification when tilted into the vertical, while a salinity front aligned with a more significant temperature front would not lead to vertical stratification dominated by salinity. Therefore, regions of $\mathrm{BL}$ formation by this method must have a spice front [fresher on one side, saltier (spicier) on the other] aligned with a density front such that

$$
\frac{\partial \rho}{\partial \tau}=\frac{-\alpha d T+\beta d S}{\alpha d T+\beta d S}>0
$$

across the spice front. When the front is tilted, the less spicy (less dense) water overlays the spicier (more dense) water, as shown by Fig. 7a, producing the slope in the density-spice plot observed in Fig. 1c. (Were the front tilted the other direction by the shear, it would create a gravitationally unstable stratification, not a BL). Creation of new BLs by advection of an existing BL [term 1 on the right side of Eq. (11)] requires $\tau_{z}<0$ in the source water. Advection of a low-salinity water mass into a high-salinity region [more akin mathematically to term 3 on the right side of Eq. (11)] requires only a difference in spice and density and horizontal velocities. At the point of formation, $\tau_{z}<0$ either due to entering a region with warmer background temperatures or cooling of the surface layer (Fig. 7b). Therefore, in order for a BL to form, $\tau_{z t}$ must be negative because any nonBL configuration will have $\tau_{z} \geq 0$.

Previous work has suggested likely formation mechanisms, primarily derived from modeling results. We use the spice framework outlined by Eq. (11) to investigate climatological patterns to infer whether these mechanisms are consistent with the observed patterns in spice. For the advection mechanism (term 1), Fig. 8 shows climatological values of $\tau_{z}$ averaged over the top $50 \mathrm{~m}$ seasonally, based on the MIMOC climatology. We find a strongly negative vertical derivative of spice, $\tau_{z}<0$, in the region of greatest BL prevalence during the northeast monsoon (DJF; Fig. 5), indicating an increase in spice with depth (Fig. 8). This pattern begins in the Bay of Bengal during the previous southwest monsoon (August) and gradually spreads into the Arabian Sea, peaking during the northeast monsoon. Prevailing near-surface currents in the SEAS are generally to the north and west during the northeast monsoon (Schott and McCreary 2001; Beal et al. 2013), suggesting advection of more negative $\tau_{z}$ into regions of less negative $\tau_{z}$. This corresponds to term 1 on the right side of Eq. (11), and is consistent with previous work identifying advection of freshwater from the Bay of Bengal within the isothermal layer as the primary mechanism for BL formation in the SEAS during the northeast monsoon (Durand et al. 2007). That $\tau_{z}$ appears strongly negative in the SEAS data on climatological scales indicates the dominance of BLs over a more traditional stratification regime in this region. Only isolated patches of $\tau_{z}<0$ appear in other seasons, consistent with the lack of large freshwater input that sets up the necessary vertical patterns on a basin scale.

Previous work on BL formation through frontal tilting [term 3 in Eq. (11)] has been focused primarily on the location of salinity fronts (e.g., CdBM2014) or the relative magnitude of horizontal salinity and temperature changes (Katsura et al. 2015). Examining the locations and alignment of spice and density fronts provides more complete information about whether the conditions meet those outlined in Fig. 7a and Eq. (12). Although we expect the position of fronts to move on a range of time scales, climatological data provide insight into whether 

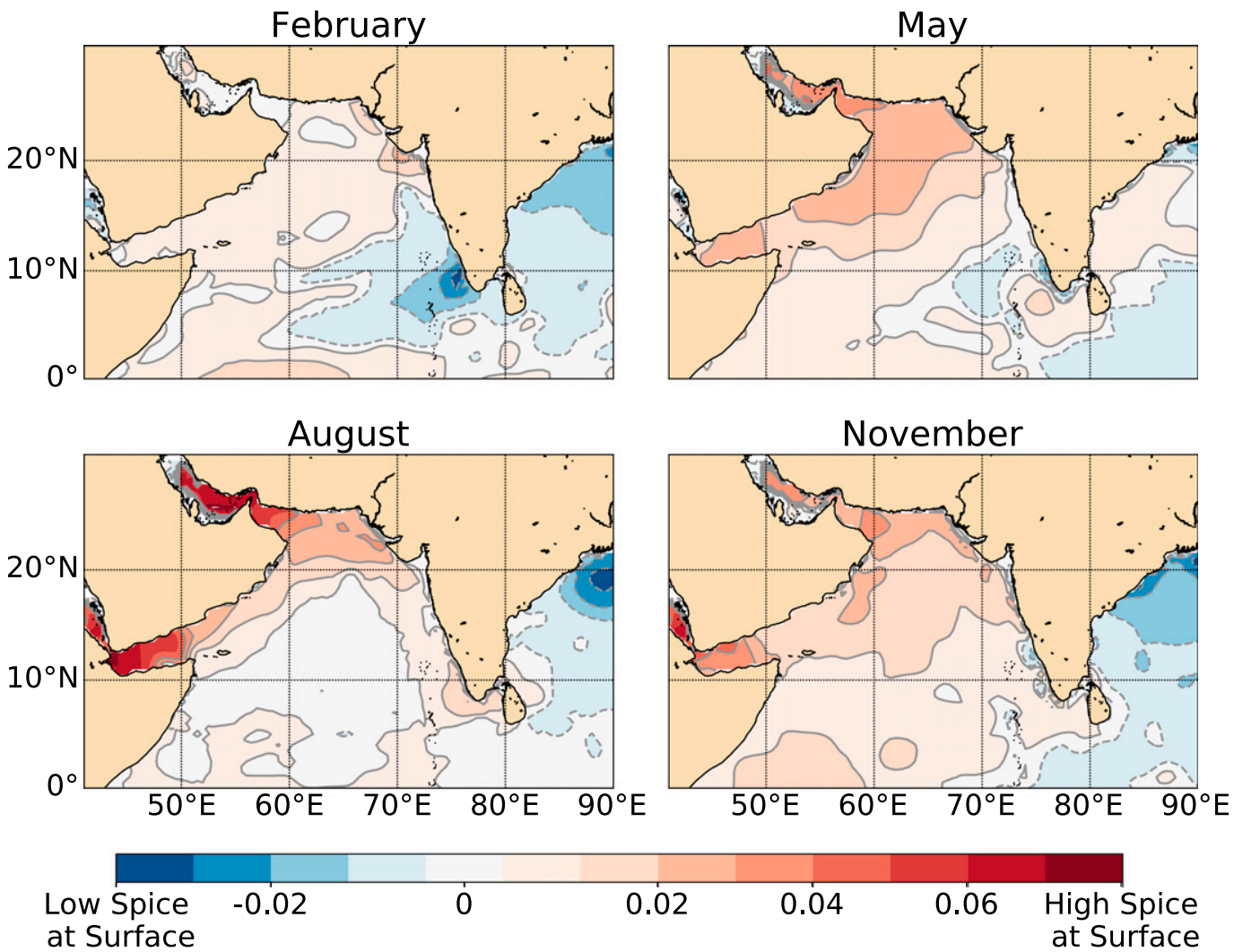

$$
\tau_{z}\left(\mathrm{~kg} \mathrm{~m}^{-4}\right)
$$

FIG. 8. Plots of vertical derivative of spice $\tau_{z}$ derived from MIMOC climatology. Blue regions indicate locations where the climatological conditions exist to allow for advection of an existing BL into an adjacent region, given suitable velocities [term 1 on right side of Eq. (11)].

those conditions are typically met. Figure 9 shows the average location of surface spice and density contours based on MIMOC data. In the south central Arabian Sea during the southwest monsoon (August) where frontal tilting has been previously discussed as a likely mechanism, (CdBM2014), we do find that the surface spice and density contours are aligned (notably between $65^{\circ}$ and $69^{\circ} \mathrm{E}$, around $7^{\circ} \mathrm{N}$ ), with density and spice increasing in the same direction. Analysis on shorter time scales using satellite data shows similar results, with frontal alignment frequently coinciding with measurement of BLs by Argo floats (not shown). Due to the strong influx of freshwater from the Bay of Bengal alternating with the advection of high-salinity water from the northern Arabian Sea, we expect strong fronts in both spice and density to occur in part of the basin during all seasons, and thus this mechanism may contribute to $\mathrm{BL}$ formation throughout the year.

Rain has been examined as a mechanism of BL formation in one-dimensional modeling studies (e.g., You 1998). The final group of terms in Eq. (11) constrain the conditions in which a BL could be formed due to surface freshwater forcing when used in conjunction with a stability scaling, such as the Monin-Obukhov length for the ocean [Eq. (13)]. The length can be interpreted as the length scale at which vertical wind mixing and atmospheric (buoyancy) forcing balance one another, with positive values indicating a stable water column. We use the definition from Large (1998) for this length $L$ in the ocean

$$
L=\frac{u_{*}^{3}}{\kappa B_{0}}
$$

where

$$
\begin{aligned}
& B_{0}=-g\left[\alpha \overline{\left(w^{\prime} T^{\prime}\right)_{0}}-\beta \overline{\left(w^{\prime} S^{\prime}\right)_{0}}\right], \\
& u_{*}=\sqrt{\frac{\Upsilon}{\rho}} .
\end{aligned}
$$

Here $\Upsilon$ is the wind stress and $\kappa$ is the von Kármán constant (0.4). From the definitions for $\overline{\left(w^{\prime} T^{\prime}\right)_{0}}$ and 

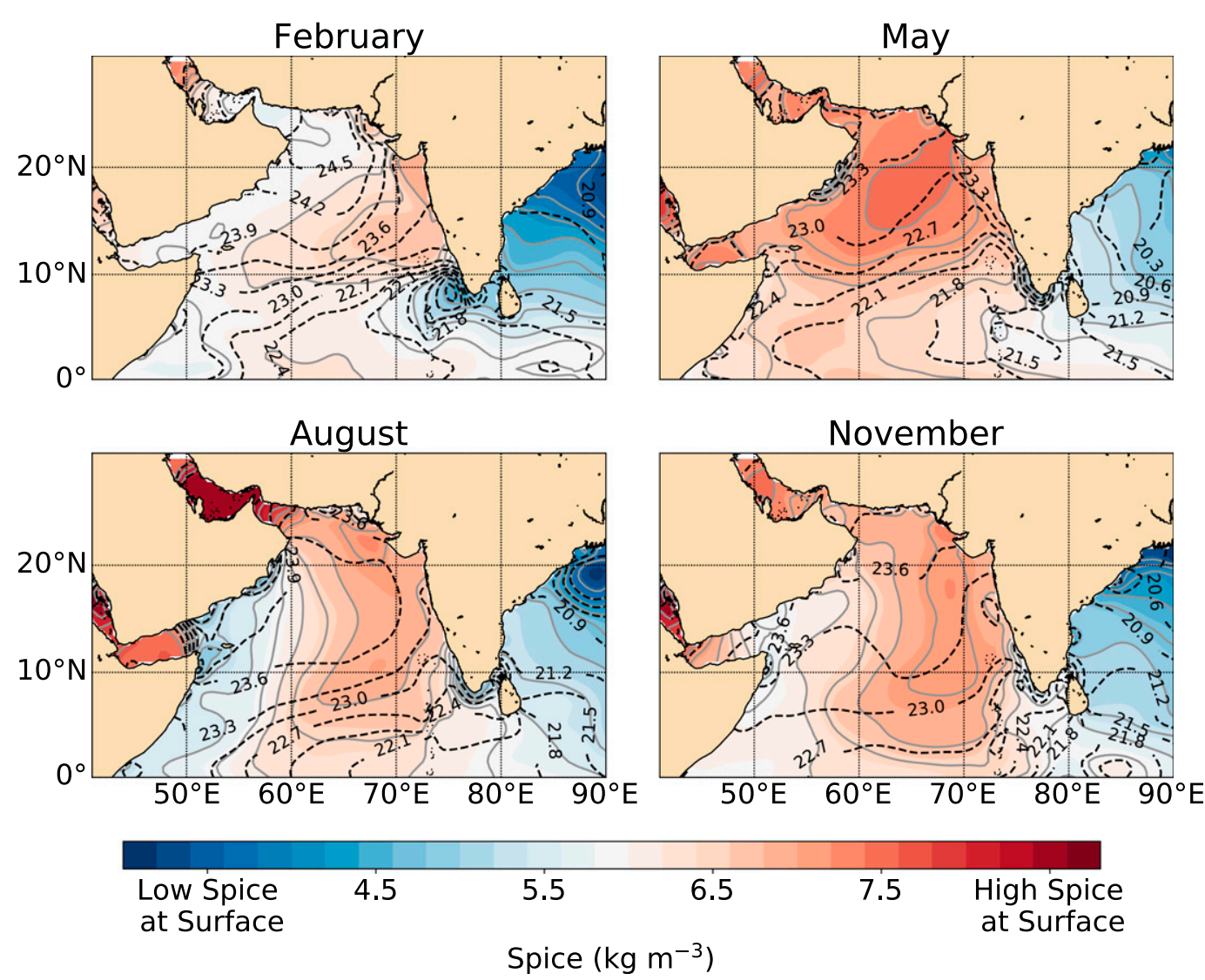

FIG. 9. Contours of spice (color shading and gray solid lines) and potential density (black dotted lines) derived from MIMOC.

$\left.\overline{\left(w^{\prime} S^{\prime}\right.}\right)_{0}$ described above, we derive the expression for buoyancy flux

$$
B_{0}=B_{H}+B_{W}=\frac{g}{\rho_{0}}\left[\frac{\alpha Q_{0}}{c_{p}}+\rho_{0} \beta S_{0}(P-E)\right],
$$

where $B_{H}$ and $B_{W}$ indicate the buoyancy forcing due to heat and freshwater flux, respectively, $(P-E)$ is expressed in units of $\mathrm{m} \mathrm{s}^{-1}$, and $B_{0}$ has units of $\mathrm{m}^{2} \mathrm{~s}^{-3}$. The term $B_{0}$ indicates the rate at which buoyancy is removed from the water column or available potential energy is supplied due to surface heat and freshwater fluxes. In the absence of atmospheric heat and freshwater fluxes, the denominator approaches zero and $L \rightarrow \infty$, indicating indefinite deepening of the ML. Positive buoyancy forcing is associated with processes that increase the stability of the ML (e.g., rain or heating) whereas negative buoyancy forcing is associated with processes that decrease the stability of the ML (e.g., evaporation or cooling). Within the classification as stable or unstable, we can attribute the stability (instability) to specific mechanisms: excess heating (cooling), excess rain (evaporation), or a combination of both. The combination of excess heating and rain will always lead to more stable conditions, just as the combination of excess cooling and evaporation will always lead to decreased stability. Simultaneous heating and evaporation or cooling and rain could cause stability to tend in either direction, depending on which forcing mechanism dominates. Stability requires that the buoyancy forcing term be positive, which further implies that

$$
-\alpha \frac{Q_{0}}{\rho_{0} C_{p}}<\beta S_{0}(P-E)
$$

establishing the relative allowed amounts of rain and cooling or heating and evaporation that will permit a stable upper ocean. To form a BL from buoyancy flux, $P-E$ must be positive (i.e., rain dominates), as must the final term from Eq. (11) above, indicating changes to the vertical spice profile due to turbulent fluxes of freshwater and heat

$$
\left\{\alpha\left[\left(\overline{w^{\prime} T^{\prime}}\right)_{z z}-\frac{1}{\rho c_{p}}\left(Q_{\mathrm{rad}}\right)_{z z}\right]+\beta\left(\overline{w^{\prime} S^{\prime}}\right)_{z z}\right\}>0 .
$$



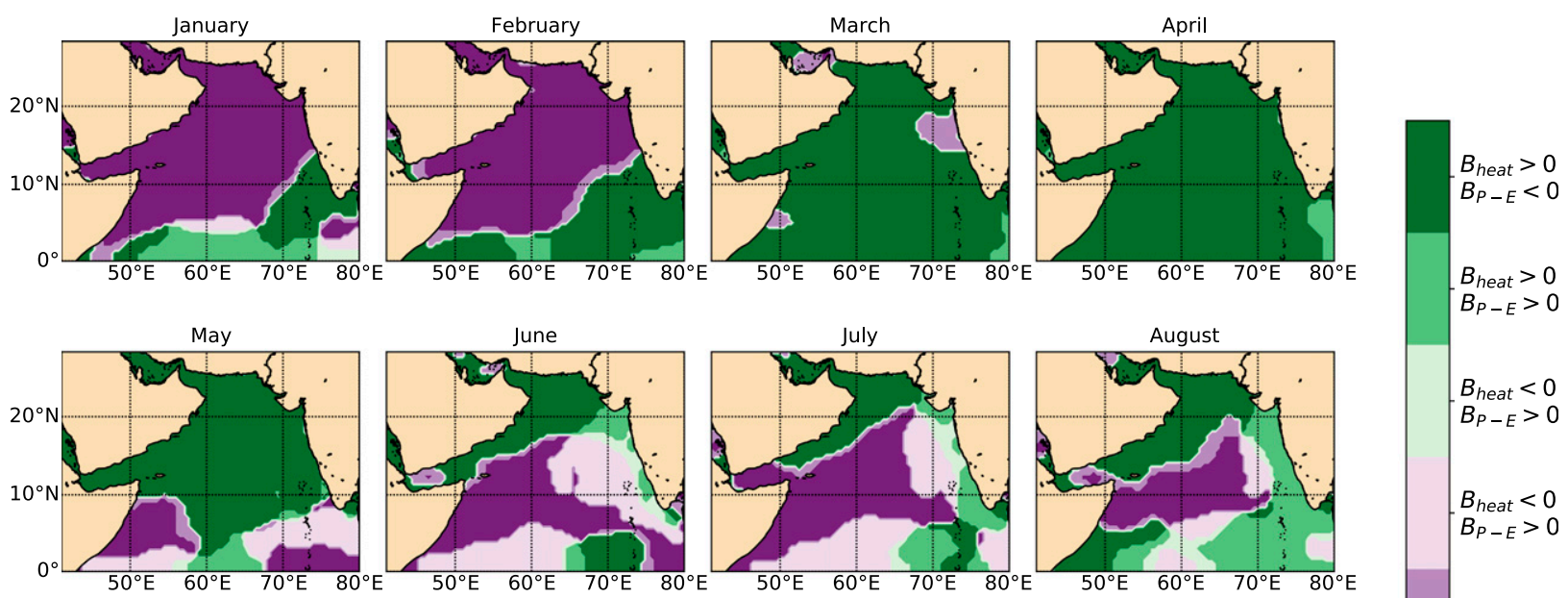

$B_{P-E}>0$
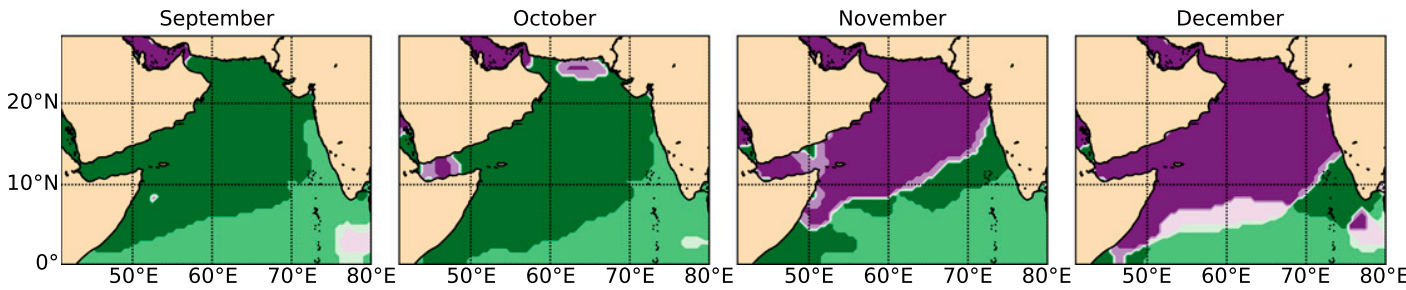

$B_{\text {heat }}<0$

$B_{P-E}>0$

$B_{\text {heat }}<0$

$B_{P-E}>0$

$B_{\text {heat }}>0$

$B_{P-E}<0$

$B_{\text {heat }}<0$

$B_{P-E}<0$

FIG. 10. Regions of Monin-Obukhov stability, shaded according to the balance of buoyancy forcing due to heat flux and buoyancy forcing due to evaporation-precipitation. Green areas are stable (consistent with hatched areas in Fig. 11), and purple areas are unstable.

A positive value for Eq. (18) would produce a negative tendency in $\tau_{z}$ as required. Between the considerations of stability [Eq. (17)], necessary freshwater forcing $(P-E>0)$, and the constraints on the spice tendency [Eq. (18)], these equations define the warming or cooling that can occur in conjunction with rain if a $\mathrm{BL}$ is to form. Although positive heat flux lends itself to stability, this effect must be minor in comparison to the freshwater flux for a BL to form. At the other extreme, however, excessive cooling at the surface will lead to gravitational instability.

Figure 10 shows regions in which rainfall may lead to BLs in the Arabian Sea, highlighted in lightest green $\left(B_{\text {heat }}<0, B_{P-E}>0\right)$; these are the regions in which cooling and freshening occur together but the freshening contributes more to changes in density, permitting stability. On a seasonal basis, the regions where BL development might be possible via rain are in the nearequatorial (medium and light green in Fig. 10) regions during the southwest monsoon. The medium green areas in Fig. $10\left(B_{\text {heat }}>0, B_{P-E}>0\right)$, showing regions of comparable rain and heating on average, may allow for BL formation if the rain overlaps with transient cooling events, such as nighttime cooling, cooling during a storm, relatively cold rainwater falling, or if the heating is very mild. In addition, the presence of BLs may insulate the ML from the effects of strong atmospheric heating by allowing increased heating below the ML by shortwave radiation (Vialard and Delecluse 1998). Regardless, it is unlikely that freshwater influx from rain could establish the same intense stratification observed due to other mechanisms, and therefore BLs formed in this way are expected to be short-lived. Thus, it seems clear that the dominant mechanisms forming BLs in this region are two-dimensional: primarily advection of freshwater and previously established BLs during the northeast monsoon (Durand et al.2007), and restratification due to tilting of frontal regions during the summer monsoon (CdBM2014).

\section{Stability and erosion of barrier layers}

The upper-ocean stability described by the MoninObukhov length also provides insight into the possible fate of BLs once formed. This is of interest because their duration and demise dictate their likely impact on SST. Figure 11 shows the seasonal distribution of BLs superimposed on the region of expected stability ( $L>0$, hatched region), inferred by using NCEP-NCAR Reanalysis-1 longterm mean atmospheric fluxes to estimate $B_{0}$ in Eq. (16). We observe that BLs are most frequently found within the stable regions during the northeast monsoon (DJF); with the exception of several small patches in regions with low BL frequency near $60^{\circ} \mathrm{E}$, BLs found in the 

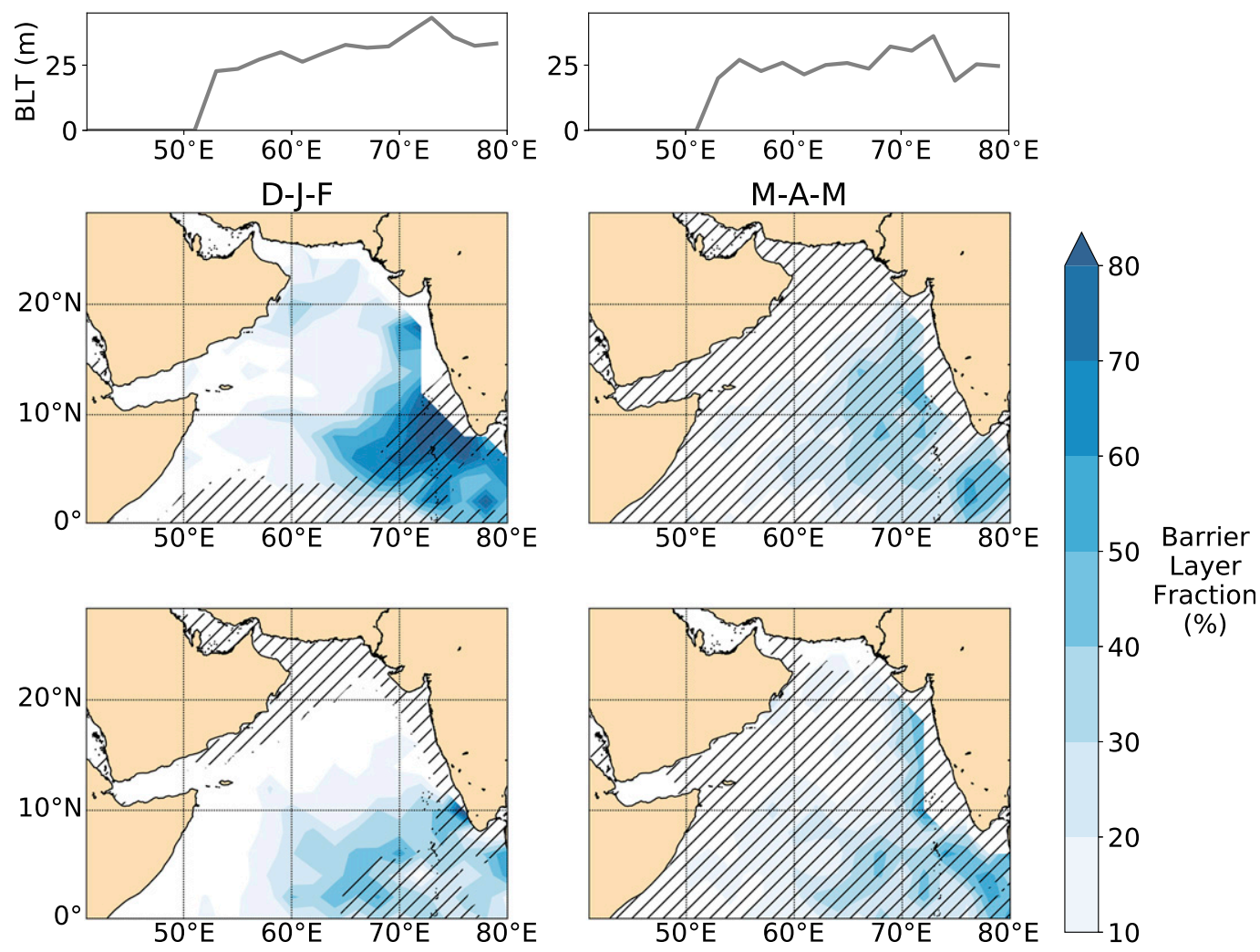

$(\%)$
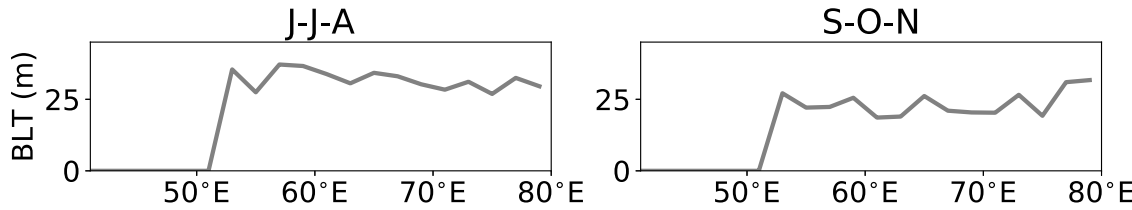

FIG. 11. Distribution of BLs (blue shading) with regions of stability derived from the Monin-Obukhov parameter (hatch marks). Estimates of stability were derived from NCEP long-term average heat fluxes and wind forcing. Line plots show meridionally averaged barrier layer thickness for each season for the dominant barrier layer regions.

stable region also tend to be thicker than outside of it (Fig. 5 contours; Fig. 11 line plots). During the southwest monsoon (JJA), BLs are often found outside of the stable region, and tend to be thicker toward the northwest (Fig. 5 contours; Fig. 11 line plots). This may in part be due to the deeper MLs typically found farther north, which would establish a deeper isothermal layer as the background for the BL prior to frontal tilting (i.e., the initial depth of the ML on the right side of the front in Fig. 7 a would be deeper, leaving a deeper lower layer after tilting).

The profiling float dataset cannot in general be used for examining possible two-dimensional mechanisms for eroding BLs. Shenoi et al. (2004) used a model to suggest the role of upwelling in eroding BLs at the end of the northeast monsoon. Here, we focus on the onedimensional turbulent fluxes, the final term in the temperature, salinity, and spice tendency equations [Eq.
(11)]. We examine the range of conditions that might erode a BL in order to suggest some broad patterns about likely mechanisms and the associated BL duration.

The limited duration of BLs derived from porosity calculations during the southwest monsoon are sometimes attributed to strong winds (e.g., CdBM2014). While winds in the northwestern portion of the basin are quite strong climatologically, particularly within the Findlater Jet (Schott and McCreary 2001), very few BLs are observed in that part of the basin. The winds in the dominant region of BL formation during the southwest monsoon are of a similar magnitude to those found during the northeast monsoon. However, Fig. 6 showed that the $\mathrm{BL}$ potential energy $P_{\mathrm{BL}}$ is roughly twice as large during the northeast monsoon (despite similar BL thickness), suggesting significantly greater resistance to wind-driven erosion. Input of turbulent kinetic energy to overcome the $\mathrm{BL}$ potential energy $P_{\mathrm{BL}}$ will have a 
greater effect with lower $P_{\mathrm{BL}}$ and higher kinetic energy input. We can estimate the rate of wind driven erosion by using a parameterization of ML deepening (McPhaden and Hayes 1991) as

$$
w_{e}=\frac{2 m\left(\frac{\rho_{a} C_{D}}{\rho_{0}}\right)^{3 / 2}|U|^{3}}{-g\left(\frac{\Delta \rho}{\rho_{0}}\right) h},
$$

where $m$ is empirically determined to represent efficiency [here we use a value of 1.25 , as discussed in the work of Niiler and Kraus (1977); Lee et al. (2000) use a different formulation for $w_{e}$ and a smaller value of $m$, but the two methods yield similar magnitudes for $w_{e}$ ], $\Delta \rho$ is the jump in density across the base of the ML, $g$ is gravity, and $\rho_{a}, C_{D}$, and $U$ are the air density, drag coefficient, and wind velocity, respectively. This parameterization only considers wind work, neglecting shear and buoyancy effects. We can create a separate estimate directly from float profiles by examining the change in ML depth between consecutive profiles $(w=d h / d t)$, which would potentially incorporate changes in ML depth due to a variety of factors. Consecutive profiles are identified by sorting all float data by WMOID number, and then sorting by date, allowing examination of all profiles for an individual float in sequence. For both cases, we only use values that indicate ML deepening, since shoaling of the ML would not contribute to BL erosion by wind. We then calculate the expected duration of the BL with

$$
\Delta t=\frac{h_{\mathrm{BL}}}{w},
$$

where $\Delta t$ is the duration of the $\mathrm{BL}, h_{\mathrm{BL}}$ is the thickness of the $\mathrm{BL}$, and $w$ is the rate of ML deepening. This is done for each individual BL profile, and then averaged by month. Figure 12a shows the expected duration of BLs in the SEAS using Eq. (20) and the different estimates of $w$. Although the estimates vary in magnitude, all suggest peak BL duration at the end of the northeast monsoon when $P_{\mathrm{BL}}$ peaks, and a minimum duration some time during the southwest monsoon (although timing differs between the methods). The $w$ calculation made directly from float profiles (green line) leads to consistently longer expected durations during the northeast and southwest monsoon. When comparing with the observed frequency (Fig. 5), the period of longest duration (the northeast monsoon) matches the period when BL are most frequent; in addition, durations on the order of 20-30 days are compatible with an observed BL frequency exceeding $60 \%$.

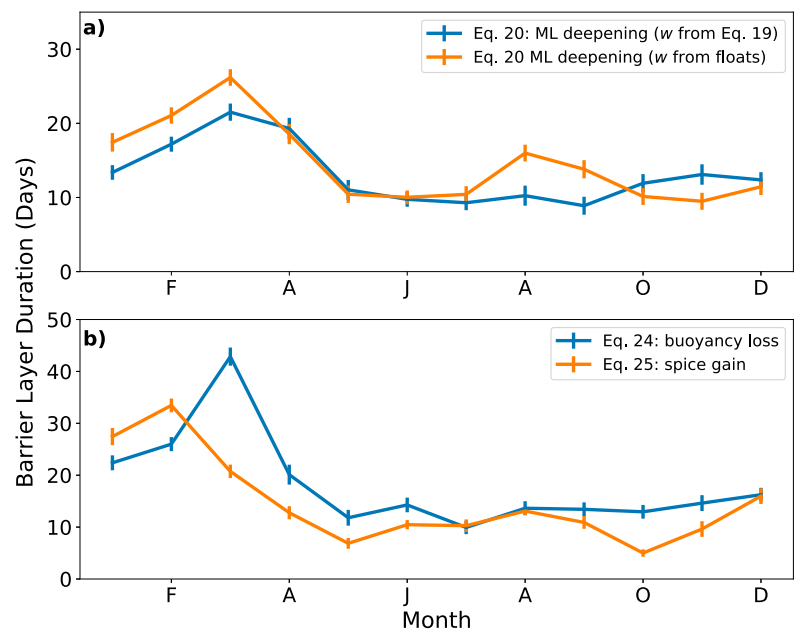

FIG. 12. Expected duration of BLs in the SEAS due to erosion by (a) ML deepening [Eq. (20)] with entrainment velocity calculated using Eq. (19) (blue line) and directly from floats (orange line) and (b) spice gain [Eq. (25)] or density changes [Eq. (24)] near the surface.

Wind mixing is not the only possible one-dimensional mechanism for BL erosion. From the examination of stability conditions in the region, it is expected that much of the basin will be unstable due to buoyancy forcing during the summer and northeast monsoons (Fig. 10). During the two intermonsoons, however, nearly the entire basin is characterized by weak winds and strong positive buoyancy forcing, primarily supplied by atmospheric heat flux. In the latter case, neither buoyancy loss nor wind-driven mixing is expected to contribute significantly to BL erosion. However, changes to the spice profile dictated by increasing temperatures at the surface could result in a thermally stratified surface layer, effectively removing the BL. Figure 3 shows several shortlived events in which the ML depth remains roughly the same but SST increases sufficiently to produce a dominant temperature stratification and high surface spice. Basin-wide temperature increases occur during both intermonsoon periods, with temperatures reaching their annual maximum prior to the onset of the southwest monsoon (Rao and Sivakumar 1999).

To perform a comparable analysis to that done with wind erosion (Fig. 12a), we define two BL characteristics, the buoyancy deficit and the spice deficit (denoted as $\Theta$ and $\Pi)$, as

$$
\begin{aligned}
& \Theta=\frac{g}{\rho_{0}} \int_{0}^{z_{\mathrm{ILD}}}\left[\sigma\left(z_{\mathrm{ILD}}\right)-\sigma\right] d z, \\
& \Pi=\frac{g}{\rho_{0}} \int_{0}^{z_{\mathrm{ILD}}}\left[\tau\left(z_{\mathrm{ILD}}\right)-\tau\right] d z,
\end{aligned}
$$

where $\Theta$ and $\Pi$ both have units of $\mathrm{m}^{2} \mathrm{~s}^{-2}$. Parameter $\Theta$ indicates the buoyancy loss necessary to eliminate the 
$\mathrm{BL}$, homogenizing the water column down to the isothermal layer depth. Parameter $\Pi$ indicates the spice gain required to overcome the effects of the salinity stratification; this does not necessarily lead to homogenization of the water column as it could occur due to a strong temperature increase at the surface, simply creating a shallow thermally stratified surface layer. We also define a parameter analogous to the buoyancy forcing to denote the effect of atmospheric forcing on the spice,

$$
\Sigma_{0}=\Sigma_{H}+\Sigma_{W}=\frac{g}{\rho_{0}}\left[\frac{\alpha Q_{0}}{c_{p}}-\rho_{0} \beta S_{0}(P-E)\right],
$$

where $\Sigma_{H}$ and $\Sigma_{W}$ indicate the spice flux due to heat and freshwater flux. The only difference between $B_{0}$ [Eq. (16)] and $\Sigma_{0}$ [Eq. (23)] is the sign of the effect of the freshwater flux, consistent with its opposite effect on buoyancy and spice. Parameters $\Theta$ and $\Pi$ can both be calculated for any BL profile, but to examine erosion times, the former is relevant for conditions in which surface buoyancy loss is occurring, the latter for situations where the ocean boundary layer is stable but the surface forcing will act to increase the surface spice. An increase in salinity at the surface would affect the buoyancy as well as the spice; however, it is the resulting changes in density that would be responsible for changes to the $\mathrm{BL}$, and in this case we would focus on buoyancy forcing as a driver of BL erosion. This encompasses all forcing conditions except those associated with BL formation during simultaneous rain and cooling.

In cases where the overall buoyancy forcing is negative (establishing conditions favorable to convective overturn), we therefore estimate the time required for this to provide the necessary buoyancy loss in the $\mathrm{BL}$ as

$$
\Delta t=\frac{\Theta}{B_{0}} .
$$

In cases where the spice forcing $\Sigma_{0}$ is positive, we estimate the time required to provide the necessary spice gain in the $\mathrm{BL}$ as

$$
\Delta t=\frac{\Pi}{\Sigma_{0}} .
$$

Determination of which equation is appropriate for estimating BL erosion time is based on float location relative to the regions in Fig. 10. The resulting estimates are for distinct sets of profiles and forcing conditions within each month.

Figure $12 \mathrm{~b}$ shows the calculated monthly erosion times derived from Eqs. (24) and (25), using gridded daily fluxes interpolated to the position of the profiles. We exclude any estimated durations longer than the maximum duration observed in the float data ( $\sim 120$ days) from the analysis. This eliminates single profiles that wildly skew the trend and does little to alter the overall patterns observed. As with wind-driven ML deepening, erosion due to buoyancy and spice forcing mechanisms both show some seasonality. Since most of the basin is dominated by positive heat fluxes in March, erosion time via buoyancy loss is quite long at that time. By contrast, the intermonsoon periods, which include March, April, and October, are times of the most rapid erosion by means of the spice mechanism (on the order of 10 days in October, for example). Regardless of mechanism, BLs are likely to persist longer during the northeast monsoon than the southwest, as all estimates of duration shown in Fig. 12 tend to be larger during the northeast monsoon, reaching the near-monthly time scales one would expect from their high prevalence in the SEAS. This reflects not only differences in the atmospheric forcing but also the BL characteristics shown in Figs. $6 \mathrm{c}$ and $6 \mathrm{f}$, and is consistent with float data showing that BLs are more likely to be observed on successive profiles during the northeast monsoon.

While the calculations that produced Fig. 12 provide insight into seasonal patterns of BL duration based on possible erosion mechanism, assessing an actual erosion mechanism associated with a specific profile is complicated. As a water column becomes vertically homogenized, we expect the magnitude of the $\tau_{\sigma \sigma}$ peaks to decrease. In the case of a purely wind-eroded BL, we would expect to see a gradual diminishing of the positive $\tau_{\sigma \sigma}$ peak signaling the base of the ML, as the ML and BL waters were entrained together, accompanied by ML deepening. If eroded by spice, we also expect a decrease in the magnitude of the $\tau_{\sigma \sigma}$ peak as thermal stratification takes over, but without the same ML deepening. This is qualitatively visible in Fig. 3. The more typical 5- or 10-day interval between measurements for most Argo-type floats does not allow for this type of detailed examination on short time scales. However, by comparing ML depths during and after the presence of a BL we can examine a range of scenarios. In both wind-driven erosion as well as erosion due to buoyancy loss (or a combination of the two), we expect to see significantly deeper MLs once the BL is eroded, consistent with the expected homogenization (in salinity and density) of the isothermal layer. However, if the BL erodes due (primarily) to increased temperature and therefore spice in the ML, we do not anticipate the same ML deepening unless also in the presence of substantial winds.

We therefore examine the ML depth after BL erosion in comparison with the ML and isothermal layer associated with the BL (Fig. 13). We assume negligible horizontal advection between measurements and therefore that observed changes are changes to the water column itself and 

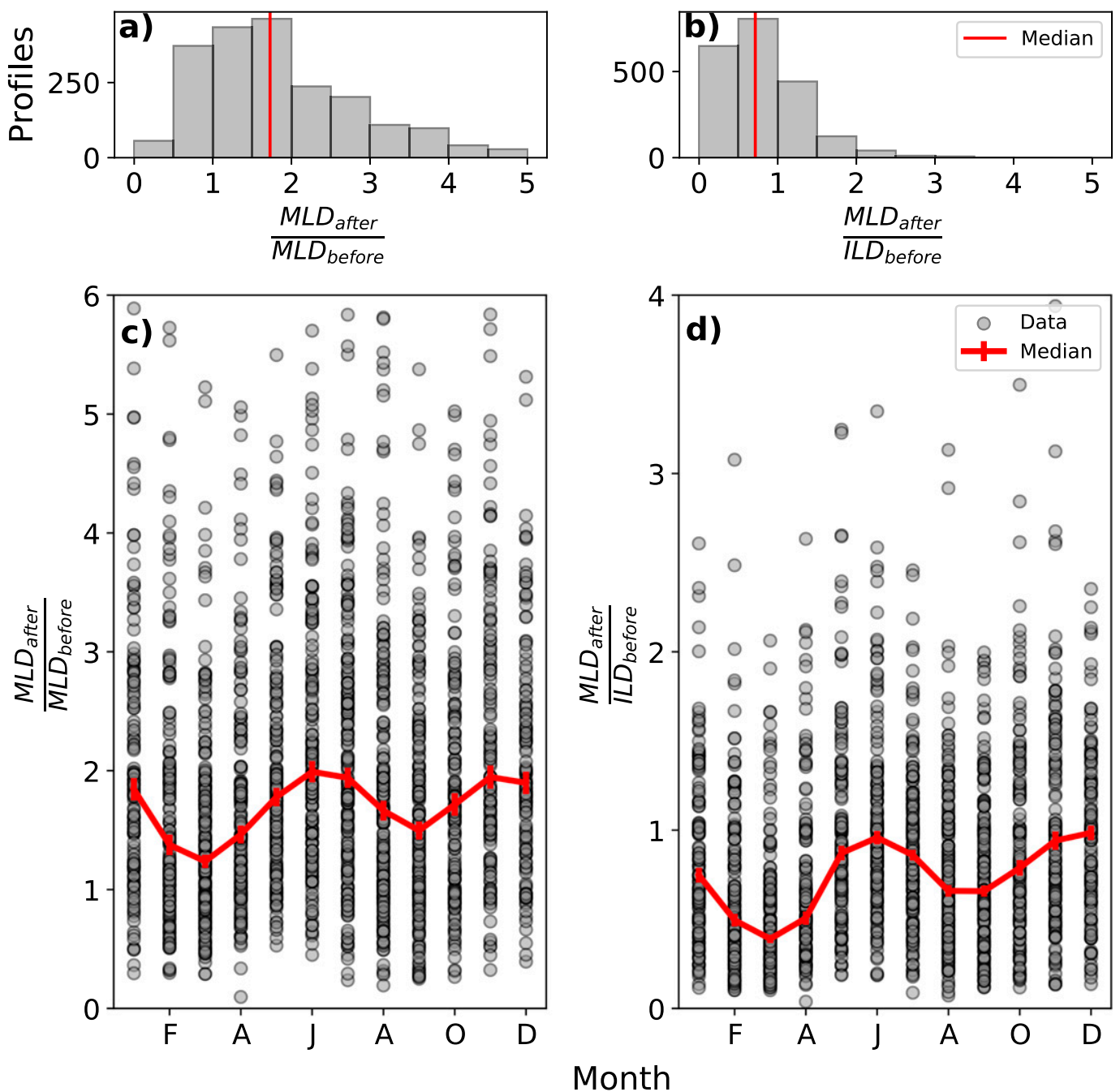

FIG. 13. Seasonal cycle of mixed layer depths in the SEAS after BL erosion normalized by (a) mixed layer depth during BL presence and (b) isothermal layer depth during BL presence. (c),(d) As in (a) and (b), but showing the same data distributed by month.

not the measurement of an entirely different portion of the ocean. Comparing ML depth during and immediately after the existence of a BL (Figs. 13a,c), a value of one indicates no change to ML depth during BL erosion. This suggests a mechanism for BL erosion through warming in the ML that was not associated with ML deepening (i.e., increased surface spice). We find this to be most commonly the case during the fall and spring intermonsoon periods (Fig. 13c), as expected from the previous analysis. These are times when strong heat flux and low winds dominate, and therefore it is unsurprising that the ML deepening is minimal and ML depths remain much shallower than the previously existing isothermal layer (values $\sim 0.5$, Fig. $13 \mathrm{~d}$ ). The most dramatic increase in ML depth upon BL erosion occurs during the southwest monsoon. This is also the season in which final ML depth most closely approximates the previous isothermal layer depth (Fig. 13d), suggesting complete erosion of the $\mathrm{BL}$ and the restoration of deep MLs. This is compatible with the short durations expected with wind driven erosion. The changes in ML density accompanying the patterns in ML depth support this assessment of likely mechanisms (not shown). In both cases, the scatterplots make the spread of the data appear quite large (Figs. 13c,d). However, from the histograms (Figs. 13a,b) we see that the majority of the data is clustered near the median values discussed above, pointing to the relevance of using the median to describe the seasonal trends.

\section{Summary and discussion}

This study focuses on the Arabian Sea due to its potential impact on the nature of the southwest monsoon. 
The results here are consistent with many previous studies, but also provide more detailed observational evidence for the presence and characteristics of barrier layers. We take advantage of the increased data provided by the Argo program and use spice as a key descriptor of barrier layers. However, the methods here could be readily applied to other low- and midlatitude regions of interest, and preliminary work in this regard captures the expected features in the Bay of Bengal, western Pacific warm pool, and the Amazon River plume, including likely formation mechanisms.

The concept of spice has been employed previously to expand insight into mixing processes in the ocean (Veronis 1972; Cole and Rudnick 2012), as well as to describe interleaving and double-diffusive processes (Flament 2002; Shcherbina et al. 2009). The present work differs from the previous studies in the type of data used (profiling floats instead of gliders and towed instruments), as well as the portion of the water column serving as the primary focus (ML instead of below the ML). Although certainly of interest when considering the duration and fate of barrier layers, using spatial and temporal changes in diapycnal spiciness curvature $\tau_{\sigma \sigma}$ to explore mixing becomes more complicated when examining the part of the ocean exposed to the atmosphere. However, using $\tau_{\sigma \sigma}$ of a single profile to identify barrier layers has several advantages over the standard threshold method used for identifying barrier layers. The central advantage is that the stratification that accompanies barrier layers has a distinct spice signature. In addition, using $\tau_{\sigma \sigma}$ avoids some of the subjectivity inherent in selecting an "appropriate" threshold, and relates to water mass evolution (Shcherbina et al. 2009), a feature that may provide insight into barrier layer evolution and behavior in the future. Unlike the threshold method, this method explicitly focuses on the barrier itself via the use of a diapycnal characteristic; thus, although the average barrier layer thicknesses identified are comparable to those found in previous studies, we suggest that there is more physical meaning to the individual values (for thickness and other characteristics) than in cases reliant on a particular threshold. It is also clear from the results here that thickness alone cannot adequately describe a barrier layer, and that other measures that characterize the resistance to erosion by various methods (e.g., barrier layer potential energy, spice deficit, and buoyancy deficit) provide more insight.

On rare occasions, the base of what is traditionally termed the "isothermal layer" may not coincide with the beginning of a true thermocline. Since $\tau_{\sigma \sigma}$ captures diapycnal changes in spice, an isopycnal layer below the barrier layer (i.e., a region with both constant temperature and constant salinity) will not be included in the barrier layer. This may help to explain some of the higher ratios seen in Fig. 13. In some cases, the ML depth after barrier layer erosion is up to 3 times deeper than the previously identified isothermal layer. In many cases, the means of erosion (e.g., surface warming) is such that the postbarrier-layer ML depth coincides closely with that of the barrier layer ML, and such deeper low-stratification regions are not relevant for erosion, nor is the main thermocline accessible as a result of the disappearance of the barrier layer. This is important when considering the impact of barrier layers on SST.

This work does not address all possible aspects of barrier layer formation and erosion; specific to the Arabian Sea, we have neglected consideration of the downwelling and upwelling in the Lakshadweep region that contribute to moving the depth of the thermocline throughout the year (Shankar et al. 2004; Shenoi et al. 1999, 2004), and more generally have not considered two-dimensional erosion mechanisms. However, one can easily imagine how the analysis that produced Fig. 8 for barrier layer formation might produce a similar result for barrier layer erosion under the appropriate circumstances: by reversing the desired sign of $\tau_{z t}$ to positive, we can identify situations in which water with high spice near the surface, or an existing barrier layer with less negative $\tau_{z}$, is carried into an area with barrier layers. In the Arabian Sea, this occurs when the currents switch direction and high-salinity water with $\tau_{z}>0$ is advected from the northern Arabian Sea to the south starting during the spring intermonsoon. This mechanism may work in tandem with the one-dimensional mechanisms explored here, particularly if strong mixing with higher-salinity water occurs (Shenoi et al. 2004). The spice framework thus allows for the identification and analysis of barrier layers using limited datasets that we expect to be applicable to other regions of the ocean beyond the Arabian Sea.

Acknowledgments. We thank K. Drushka and M. Cronin, as well as two anonymous reviewers, for their constructive feedback and suggestions. This material is based upon work supported by the National Science Foundation Graduate Research Fellowship Program under Grant DGE-1762114. Any opinions, findings, and conclusions or recommendations expressed in this material are those of the author(s) and do not necessarily reflect the views of the National Science Foundation. We also gratefully acknowledge the generous support of Office of Naval Research through the NASCar Grant N00014-15-1-2254 and NOAA Grant NA15OAR4320063 to the University of Washington, through the Joint Institute for the Study of the Ocean and the Atmosphere. 
These data were collected and made freely available by the International Argo Program and the national programs that contribute to it. (http://www.argo.ucsd.edu, http://argo.jcommops.org, http://doi.org/10.17882/42182). The Argo Program is part of the Global Ocean Observing System. NCEP-DOE 2 Reanalysis data provided by the NOAA/OAR/ESRL PSD, Boulder, Colorado, USA, from their website at https://www.esrl.noaa.gov/psd/.

\section{REFERENCES}

Agarwal, N., R. Sharma, A. Parekh, S. Basu, A. Sarkar, and V. K. Agarwal, 2012: Argo observations of barrier layer in the tropical Indian Ocean. Adv. Space Res., 50, 642-654, https:// doi.org/10.1016/j.asr.2012.05.021.

Balaguru, K., P. Chang, R. Saravanan, L. R. Leung, Z. Xu, M. Li, and J.-S. Hsieh, 2012: Ocean barrier layers' effect on tropical cyclone intensification. Proc. Natl. Acad. Sci. USA, 109, 14343-14347, https://doi.org/10.1073/pnas.1201364109.

Beal, L., V. Hormann, R. Lumpkin, and G. R. Foltz, 2013: The response of the surface circulation of the Arabian Sea to monsoonal forcing. J. Phys. Oceanogr., 43, 2008-2022, https:// doi.org/10.1175/JPO-D-13-033.1.

Chi, N.-H., R.-C. Lien, E. A. D'Asaro, and B. B. Ma, 2014: The surface mixed layer heat budget from mooring observations in the central Indian Ocean during Madden-Julian Oscillation events. J. Geophys. Res. Oceans, 119, 4638-4652, https:// doi.org/10.1002/2014JC010192.

Cole, S. T., and D. L. Rudnick, 2012: The spatial distribution and annual cycle of upper ocean thermohaline structure. J. Geophys. Res., 117, C02027, https://doi.org/10.1029/ 2011JC007033.

Cronin, M. F., and M. J. McPhaden, 2002: Barrier layer formation during westerly wind bursts. J. Geophys. Res., 107, 8020, https://doi.org/10.1029/2001JC001171.

de Boyer Montégut, C., F. Durand, R. Bourdallé-Badie, and B. Blanke, 2014: Role of fronts in the formation of Arabian Sea barrier layers during summer monsoon. Ocean Dyn., 64, 809-822, https://doi.org/10.1007/s10236-014-0716-7.

Durand, F., S. R. Shetye, J. Vialard, D. Shankar, S. S. C. Shenoi, C. Ethe, and G. Madec, 2004: Impact of temperature inversions on SST evolution in the south-eastern Arabian Sea during the pre-summer monsoon season. Geophys. Res. Lett., 31, L01305, https://doi.org/10.1029/ 2003GL018906.

- D. Shankar, C. de Boyer Montégut, S. S. C. Shenoi, B. Blanke, and G. Madec, 2007: Modeling the barrier-layer formation in the southeastern Arabian Sea. J. Climate, 20, 2109-2120, https://doi.org/10.1175/JCLI4112.1.

Feistel, R., 2003: A new extended Gibbs thermodynamic potential of seawater. Prog. Oceanogr., 58, 43-114, https://doi.org/ 10.1016/S0079-6611(03)00088-0.

Ffield, A., 2007: Amazon and Orinoco river plumes and NBC rings: Bystanders or participants in hurricane events? J. Climate, 20 316-333, https://doi.org/10.1175/JCLI3985.1.

Flament, P., 2002: A state variable for characterizing water masses and their diffusive stability: Spiciness. Prog. Oceanogr., 54, 493-501, https://doi.org/10.1016/S00796611(02)00065-4.

IOC, SCOR, and IAPSO, 2010: The international thermodynamic equation of seawater-2010: Calculation and use of thermodynamic properties. Intergovernmental Oceanographic Commission, Manuals and Guides 56, UNESCO, 196 pp., http://www.teos-10.org/pubs/TEOS-10_Manual.pdf.

Jackett, D. R., and T. J. McDougall, 1985: An oceanographic variable for the characterization of intrusions and water masses. Deep-Sea Res., 32A, 1195-1207, https://doi.org/10.1016/01980149(85)90003-2.

Kanamitsu, M., W. Ebisuzaki, J. Woollen, S.-K. Yang, J. J. Hnilo, M. Fiorino, and G. L. Potter, 2002: NCEP-DOE AMIP-II Reanalysis (R-2). Bull. Amer. Meteor. Soc., 83, 1631-1643, https://doi.org/10.1175/BAMS-83-11-1631.

Kara, A. B., P. A. Rochford, and H. E. Hurlburt, 2000: Mixed layer depth variability and barrier layer formation over the North Pacific Ocean. J. Geophys. Res., 105, 16 783-16801, https:// doi.org/10.1029/2000JC900071.

Katsura, S., E. Oka, and K. Sato, 2015: Formation mechanism of barrier layer in the subtropical Pacific. J. Phys. Oceanogr., 45, 2790-2805, https://doi.org/10.1175/JPO-D15-0028.1.

Large, W., 1998: Modeling and parameterizing the ocean planetary boundary layer. Ocean Modeling and Parameterization, E. P. Chassignet and J. Verron, Eds., Kluwer Academic Publishers, 81-120.

Lee, C. M., B. H. Jones, K. H. Brink, and A. S. Fischer, 2000: The upper-ocean response to monsoonal forcing in the Arabian Sea: Seasonal and spatial variability. Deep-Sea Res. II, 47, 1177-1226, https://doi.org/10.1016/S09670645(99)00141-1.

Lorbacher, K., D. Dommenget, P. P. Niiler, and A. Köhl, 2006: Ocean mixed layer depth: A subsurface proxy of ocean- atmosphere variability. J. Geophys. Res., 111, C07010, https:// doi.org/10.1029/2003JC002157.

Lukas, R., and E. Lindstrom, 1991: The mixed layer of the western equatorial Pacific Ocean. J. Geophys. Res., 96, 3343-3357, https://doi.org/10.1029/90JC01951.

Masson, S., and Coauthors, 2005: Impact of barrier layer on winter-spring variability of the southeastern Arabian Sea. Geophys. Res. Lett., 32, L07703, https://doi.org/10.1029/ 2004GL021980.

McDougall, T. J., and O. A. Krzysik, 2015: Spiciness. J. Mar. Res., 73, 141-152, https://doi.org/10.1357/002224015816665589.

McPhaden, M. J., and S. P. Hayes, 1991: On the variability of winds, sea surface temperature, and surface layer heat content in the western equatorial Pacific. J. Geophys. Res., 96, 3331-3342, https://doi.org/10.1029/90JC01726.

Mignot, J., C. de Boyer Montégut, and M. Tomczak, 2009: On the porosity of barrier layers. Ocean Sci., 5, 379-387, https:// doi.org/10.5194/os-5-379-2009.

Niiler, P. P., and E. B. Kraus, 1977: One-dimensional models of the upper ocean. Modelling and Prediction of the Upper Layers of the Ocean, E. B. Kraus, Ed., Pergamon, 143-172.

Qu, T., and G. Meyers, 2005: Seasonal variation of barrier layer in the southeastern tropical Indian Ocean. J. Geophys. Res., 110, C11003, https://doi.org/10.1029/2004JC002816.

Rao, R. R., and R. Sivakumar, 1999: On the possible mechanisms of the evolution of a mini-warm pool during the pre-summer monsoon season and the genesis of onset vortex in the southeast Arabian Sea. Quart. J. Roy. Meteor. Soc., 125, 787-809, https://doi.org/10.1002/QJ.49712555503.

Schmidtko, S., G. C. Johnson, and J. M. Lyman, 2013: MIMOC: A global monthly isopycnal upper-ocean climatology with mixed layers. J. Geophys. Res. Oceans, 118, 1658-1672, https:// doi.org/10.1002/JGRC.20122. 
Schmitt, R. W., 1981: Form of the temperature-salinity relationship in the Central Water: Evidence for double-diffusive mixing. J. Phys. Oceanogr., 11, 1015-1026, https://doi.org/10.1175/ 1520-0485(1981)011<1015:FOTTSR > 2.0.CO;2.

- 1990: On the density ratio balance in the Central Water. J. Phys. Oceanogr., 20, 900-906, https://doi.org/10.1175/15200485(1990)020<0900:OTDRBI > 2.0.CO;2.

Schott, F. A., and J. P. McCreary, 2001: The monsoon circulation of the Indian Ocean. Prog. Oceanogr., 51, 1-123, https://doi.org/ 10.1016/S0079-6611(01)00083-0.

Shankar, D., and Coauthors, 2004: Observational evidence for westward propagation of temperature inversions in the southeastern Arabian Sea. Geophys. Res. Lett., 31, L08305, https://doi.org/10.1029/2004GL019652.

Shcherbina, A. Y., M. C. Gregg, M. H. Alford, and R. R. Harcourt, 2009: Characterizing thermohaline intrusions in the North Pacific subtropical frontal zone. J. Phys. Oceanogr., 39, 27352756, https://doi.org/10.1175/2009JPO4190.1.

Shenoi, S. S. C., D. Shankar, and S. R. Shetye, 1999: On the sea surface temperature high in the Lakshadweep Sea before the onset of the southwest monsoon. J. Geophys. Res., 104, 15 70315 712, https://doi.org/10.1029/1998JC900080.
- — - and — 2004: Remote forcing annihilates barrier layer in southeastern Arabian Sea. Geophys. Res. Lett., 31, L05307, https://doi.org/10.1029/2003GL019270.

Sprintall, J., and M. Tomczak, 1992: Evidence of the barrier layer in the surface layer of the tropics. J. Geophys. Res., 97, 73057316, https://doi.org/10.1029/92JC00407.

Thadathil, P., and Coauthors, 2008: Seasonal variability of the observed barrier layer in the Arabian Sea. J. Phys. Oceanogr., 38, 624-638, https://doi.org/10.1175/2007JPO3798.1.

Veronis, G., 1972: On properties of seawater defined by temperature, salinity, and pressure. J. Mar. Res., 30, 227-255.

Vialard, J., and P. Delecluse, 1998: An OGCM study for the TOGA decade. Part 1: Role of salinity in the physics of the western Pacific fresh pool. J. Phys. Oceanogr., 28, 1071-1088, https://doi.org/10.1175/1520-0485(1998)028<1071:AOSFTT > 2.0.CO;2.

Vinayachandran, P., D. Shankar, J. Kurian, F. Durand, and S. S. C. Shenoi, 2007: Arabian Sea mini warm pool and the monsoon onset vortex. Curr. Sci., 93, 203-214.

You, Y., 1998: Rain-formed barrier layer of the western equatorial Pacific warm pool: A case study. J. Geophys. Res., 103, 53615378, https://doi.org/10.1029/97JC03421. 